\title{
Constitutively expressed Protocadherin- $\alpha$ regulates the coalescence and elimination of homotypic olfactory axons through its cytoplasmic region
}

\author{
Sonoko Hasegawa ${ }^{1}$, Takahiro Hirabayashi ${ }^{1}$, Takahiko Kondo ${ }^{1}$, Ken Inoue ${ }^{1}$, Shigeyuki Esumi ${ }^{1,2}$, \\ Atsushi Okayama ${ }^{1}$, Shun Hamada ${ }^{1,3}$ and Takeshi Yagi ${ }^{1 *}$
}

' KOKORO-Biology Group and CREST-JST, Laboratories for Integrated Biology, Graduate School of Frontier Biosciences, Osaka University, Osaka, Japan

2 Department of Morphological Neural Science, Graduate School of Medical Sciences, Kumamoto University, Kumamoto, Japan

${ }^{3}$ Department of Nutrition and Health Sciences, Fukuoka Women's University, Fukuoka, Japan

Edited by:

Alistair N. Garratt, Max Delbrück

Center for Molecular Medicine,

Germany

Reviewed by:

Alistair N. Garratt, Max Delbrück

Center for Molecular Medicine,

Germany

Andrew Chess, Mount Sinai School

of Medicine, USA

${ }^{*}$ Correspondence:

Takeshi Yagi, Graduate School of

Frontier Biosciences, Osaka

University, 1-3 Yamadaoka, Suita,

Osaka 565-0871, Japan.

e-mail: yagi@fbs.osaka-u.ac.jp.
Olfactory sensory neuron (OSN) axons coalesce into specific glomeruli in the olfactory bulb (OB) according to their odorant receptor (OR) expression. Several guidance molecules enhance the coalescence of homotypic OSN projections, in an OR-specific- and neural-activity-dependent manner. However, the mechanism by which homotypic OSN axons are organized into glomeruli is unsolved. We previously reported that the clustered protocadherin- $\alpha$ (Pcdh- $\alpha$ ) family of diverse cadherin-related molecules plays roles in the coalescence and elimination of homotypic OSN axons throughout development. Here we showed that the elimination of small ectopic homotypic glomeruli required the constitutive expression of a Pcdh- $\alpha$ isoform and Pcdh- $\alpha$ 's cytoplasmic region, but not OR specificity or neural activity. These results suggest that Pcdh- $\alpha$ proteins provide a cytoplasmic signal to regulate repulsive activity for homotypic OSN axons independently of OR expression and neural activity. The counterbalancing effect of Pcdh- $\alpha$ proteins for the axonal coalescence mechanisms mediated by other olfactory guidance molecules indicate a possible mechanism for the organization of homotypic OSN axons into glomeruli during development.

Keywords: olfactory, axon, protocadherin, Pcdh, convergence, elimination, neural circuit, neuron

\section{INTRODUCTION}

The olfactory system can recognize and discriminate an enormous number of odor molecules in the external environment. In this system, individual olfactory sensory neurons (OSNs) in the olfactory epithelium $(\mathrm{OE})$ express only one type of functional odorant receptor $(\mathrm{OR})$ from $\sim 1000$ genes in mice (Buck and Axel, 1991; Chess et al., 1994; Malnic et al., 1999). The OSNs expressing one type of OR project and coalesce their axons into specific glomeruli that are spatially arranged on the surface of the olfactory bulb (OB) (Ressler et al., 1994; Vassar et al., 1994; Mombaerts et al., 1996).

The coalescence of OSN axons into glomeruli is directed by the expressed OR and is dependent on neural activity (Feinstein and Mombaerts, 2004; Feinstein et al., 2004; Mombaerts, 2006; Serizawa et al., 2006). In this process, guidance molecules including cell adhesion molecules and receptors organize the OSN axon projections; these guidance molecules include ephrin/Eph, Semaphorin/neuropilin, Plexin, BIG-2, and Kirrel2/3 (Schwarting et al., 2000, 2004; Walz et al., 2002; Cutforth et al., 2003; Taniguchi et al., 2003; Imai et al., 2006; Serizawa et al., 2006; Col et al., 2007; Kaneko-Goto et al., 2008; Takeuchi et al., 2010). The expression levels of these guidance molecules in the OSNs are regulated by OR-derived signals and the anatomical location of the OSNs in the OE, resulting in the coalescence of homotypic OSNs. Thus, the distinct expression levels and combinations of guidance molecules in the OSNs constitute one basic mechanism for the approximate projection and coalescence of OSN axons.

The protocadherin- $\alpha(P c d h-\alpha)$ genes belong to the clustered Pcdh families, which encode cadherin-related proteins with distinct domains derived from multiple variable exons: six extracellular cadherin domains, a transmembrane domain, and a short cytoplasmic domain (Kohmura et al., 1998; Wu and Maniatis, 1999; Yagi, 2012). They also have a common cytoplasmic tail (type A or B) derived from three or four constant exons (Kohmura et al., 1998; Sugino et al., 2000). The diverse Pcdh- $\alpha$ molecules are required for the coalescence of homotypic OSN axons into the OR-specific glomeruli of the OB (Hasegawa et al., 2008).

To address the functional significance of the diversity of Pcdh$\alpha$ proteins, here we produced mutants in which exons $\alpha 2-\alpha C 2$, i.e., all but exon $\alpha 1$, were deleted in the variable region of the $P c d h-\alpha$ cluster. Surprisingly, in the mutant mice, the remaining $\alpha 1$ isoform compensated for the others, and was constitutively expressed in the neurons including OSNs. The coalescence of OSN projections in these mutants looked normal. In contrast, loss of the common cytoplasmic region from the Pcdh- $\alpha$ proteins disrupted the axonal coalescence. These findings indicate that constitutively expressed Pcdh- $\alpha$ proteins provide a cytoplasmic signal to regulate axonal coalescence and eliminate ectopic glomeruli. We also showed that the expression and function of 
Pcdh- $\alpha$ were not dependent on either OR-specific signaling or OSN-derived neural activity. Based on these results, we propose that Pcdh- $\alpha$ has an activity that causes repulsion (or elimination) in homotypic OSN axons, that is different from the coalescence activity provided by other olfactory guidance molecules.

\section{MATERIALS AND METHODS ANIMAL EXPERIMENTS}

All the experimental procedures were in accordance with the Guide for the Care and Use of Laboratory Animals of the Science Council of Japan and were approved by the Animal Experiment Committee of Osaka University.

\section{GENERATION OF Pedh- $\alpha$ MUTANT MICE}

Similar to produce $P c d h a^{\Delta C R / \triangle C R}$ mice (Hasegawa et al., 2008), we generated $P c d h a^{\triangle C R 2 / \triangle C R 2}$ mice using the CAG-Cre transgene and two targeted mutations: one GlloxP allele and another $\Delta A$ allele (Katori et al., 2009). The $P c d h a^{\Delta C R 2 / \triangle C R 2}$ mice expressed no Pcdh- $\alpha$ protein similar to $P c d h a^{\Delta C R / \triangle C R}$ mice (data not shown).

By mating G16Neo mutant mice, in which two loxP sites were inserted between exons $\alpha 1$ and $\alpha 2$ (Noguchi et al., 2009), G1loxP mice in which a loxP site was inserted between exons $\alpha c 2$ and $\alpha C R 1$ (Hasegawa et al., 2008), and synaptosomal complex protein1 (Sycp)-Cre transgenic mice (Noguchi et al., 2009), male mice carrying the G16Neo allele, G1loxP allele, and Sycp-Cre transgene were generated. These mice were crossed with $\mathrm{C} 57 \mathrm{BL} / 6$ females, and the genotypes of pups were determined by Southern blotting using probes amplified by PCR with Probe-G16F (5'-GGAGGACATGCACAAGTCATG-3') and Probe-G16-R (5'-TTGTGGTGTACAGCGACACC- $\left.3^{\prime}\right)$ primers, and by PCR using G16 primer (5'-GGCTATCCTGTGCTACAGAAC-3'), G16GTP-R2 primer ( $5^{\prime}$-CCAATTAATATTTGAGATTCATCCCC-3'), and G1-GTP-R primer (5'- GCCCAGGATGGCTCAAATTC$\left.3^{\prime}\right)$. Some pups carried the $P c d h a^{\Delta(2-c 2)}$ or the $P c d h a^{d u p(2-c 2)}$ allele generated by trans-allelic targeted meiotic recombination (TAMERE) in the testis (Herault et al., 1998) (Figure 5). $P c d h a^{\triangle A / \Delta A}$ mutant mice with a truncated $\mathrm{Pcdh}-\alpha$ protein were described previously (Katori et al., 2009).

\section{RT-PCR}

Total RNA from mouse whole brain was extracted with TRIzol Reagent (Life Technologies), and the cDNAs were synthesized using SuperScriptIII reverse transcriptase (Life Technologies), according to the manufacturer's protocol. Forward primers were $\alpha 1,5^{\prime}$-GTGACCACGCAGAAGTAAAT-3 ${ }^{\prime} ; \quad \alpha 2,5^{\prime}$-GA AGAGAGACAACCACCCTT- $3^{\prime} ; \alpha 3,5^{\prime}$-GACAAACTGGTTGG AGACAT- $3^{\prime} ; \quad \alpha 4, \quad 5^{\prime}$-CAATTGCAGTCTGCAGAGGA- $3^{\prime} ; \alpha 5$, $5^{\prime}$-ACCTCAGGGACCCAGCTCTA-3'; $\alpha 6,5^{\prime}$-GCATCAGGATT TGAACGACG- $3^{\prime} ; \quad \alpha 7, \quad 5^{\prime}$-CCTACCTCAGGGTCCCAGCT- ${ }^{\prime}$; $\alpha 8,5^{\prime}$-CCATCTGTTTCTTTGGACTC-3'; $\alpha 9,5^{\prime}$-GGAAAGTCA TTCTGTTGGAG-3'; $\alpha 10,5^{\prime}$-GGTTCTGGAGATAGTGGAGT-3'; $\alpha 11, \quad 5^{\prime}$-GGAAAGACAGGAGTCAGAGT-3'; $\alpha 12, \quad 5^{\prime}$-GTCA GAGAGAAAGGCAGGTA- $3^{\prime} ; \quad \alpha c 1, \quad 5^{\prime}$-GGGGATCATTCAAA TGTGGA-3'; $\quad \alpha c 2, \quad 5^{\prime}$-CCGGGAACCTGATTATCCTA- $3^{\prime}$, and reverse primer was $\alpha C R 5^{\prime}$-GACTGTTTGGGGTTGCC- $3^{\prime}$. Quantitative PCR analysis was performed with the SYBR
Green Master Mix (Life Technologies) using ABI 7900HT (Life Technologies) with primers for $\alpha 1,5^{\prime}$-CCCAGGTTTGAAC ATAGGC-3' and 5'-CGAGGCAGAGTAGCGCC-3'; for $\alpha C R$, $5^{\prime}$-AGAGCAGGCATGCACAGC-3' and $5^{\prime}$-GACTGTTTGGGG TTGCC-3'; GAPDH, 5' -GACTTCAACAGCAACTCCCAC-3' and $5^{\prime}$-TCCACCACCCTGTTGCTGTAG-3'. For statistical analysis of the qPCR data, One-Way ANOVA, Tukey's test was used.

\section{SINGLE CELL RT-PCR}

Single cell RT-PCR analysis of OSNs was performed as described previously (Esumi et al., 2005). Briefly, single OSNs were obtained from the OE of adult OMP-GFP mice (a generous gift from Dr. Mombaerts). We picked up single GFP-positive OSNs with a glass capillary and placed them in individual PCR tubes. After cDNA synthesis from the single cells, the first multiplex PCR was performed using a $5^{\prime}$ PCR primer designed to contain a consensus sequence common to all the variable exons of the $P c d h-\alpha$ family. Next, we amplified each $P c d h-\alpha$ isoform using a specific primer pair and semi-nested second PCR. Finally, we directly sequenced the PCR-amplified products to identify which $P c d h-\alpha$ mRNAs were expressed in individual cells.

\section{IMMUNOBLOT ANALYSIS}

Mouse whole brains were homogenized in $0.32 \mathrm{M}$ sucrose containing $1 \mathrm{mM}$ EDTA and protease inhibitors, with a Dounce homogenizer. The homogenates were spun at $800 \times \mathrm{g}$ for $10 \mathrm{~min}$. The supernatants were spun at $20,000 \times \mathrm{g}$ at $4^{\circ} \mathrm{C}$ for $30 \mathrm{~min}$. The pellets were lysed with lysis buffer $(20 \mathrm{mM}$ Tris- $\mathrm{HCl}, \mathrm{pH}$ 7.5, $150 \mathrm{mM} \mathrm{NaCl}, 1 \mathrm{mM}$ EDTA, $1 \%$ Triton X-100, protease inhibitors) and spun at $20,000 \times \mathrm{g}$ at $4^{\circ} \mathrm{C}$ for $30 \mathrm{~min}$. The supernatants were subjected to SDS-PAGE followed by immunoblot analysis using a rabbit anti-Pcdha antibody (Murata et al., 2004).

\section{In situ HYBRIDIZATION HISTOCHEMISTRY}

In situ hybridization histochemistry was performed as described previously (Katori et al., 2009; Noguchi et al., 2009). Briefly, $10 \mu \mathrm{m}$-thick fresh-frozen sections were prepared and hybridized with a constant-region cRNA probe for $\alpha 4$ cDNA (nucleotides 2518-4559) to detect all the Pcdh- $\alpha$ mRNA members. To detect certain variable isoforms of the $P c d h-\alpha$ mRNAs, probes for $\alpha 1$ cDNA (nucleotides 396-1134), and $\alpha 11$ cDNA (nucleotides 3982367) were used.

\section{IMMUNOHISTOCHEMISTRY}

Immunohistochemistry was performed as described previously (Hasegawa et al., 2008). We used antibodies against mOR-EG and MOR28, kindly given by Dr. Yoshihara, and a rabbit anti-Pcdh $\alpha$ CR antibody, a generous gift from Dr. Watanabe.

\section{$\beta$-GALACTOSIDASE HISTOCHEMISTRY}

$\beta$-galactosidase histochemistry was performed as described previously (Hasegawa et al., 2008). Littermates from $P c d h a^{+/ \Delta C R}$, $P c d h a^{+/ \Delta C R 2}, P c d h a^{+/ \Delta(2-c 2)}$, and $P c d h a^{+/ \Delta A}$ heterozygous parents were examined to compare WT and mutant mice that were also homozygous for M71-IRES-taulacZ, MOR23-IRES-taulacZ, or P2-IRES-taulacZ (kindly provided from Dr. Mombaerts). For this study, we mainly used $P c d h a^{\Delta C R / \triangle C R}$ mice, except for 
counting the P2 glomeruli at P7 and P30, for which we used $P c d h a^{\triangle C R 2 / \triangle C R 2}$ mice. The phenotypes described in this study were similar for these strains (see Table $\mathbf{1}$ ).

\section{UNILATERAL NARIS OCCLUSION}

Unilateral naris occlusion was performed as described previously (Philpot et al., 1997).

\section{IMAGE ANALYSIS}

Fluorescent digital images were captured using a fluorescence microscope (Olympus BX51) equipped with a DP50 CCD camera (Olympus).

\section{STATISTICAL ANALYSIS}

Statistical analysis was conducted using StatView J-4.5 (SAS Institute, Cary, NC). Comparison of the number of glomeruli was performed by the Mann-Whitney test. Values in graphs were expressed as the mean \pm SEM.

\section{RESULTS}

\section{ABNORMAL AXONAL COALESCENCE OF THE OSNs IN Pcdh- $\alpha$ MUTANTS}

The diverse $P c d h-\alpha$ family is required for the normal coalescence of OSN axons into glomeruli and for the elimination of ectopic glomeruli in the OB. In Pcdh- $\alpha$-deficient mice, abnormal, small ectopic glomeruli are observed for OSNs expressing the M71, M72, and MOR23 ORs (Hasegawa et al., 2008). To confirm whether Pcdh- $\alpha$ is involved in the axonal coalescence of homotypic OSNs in the glomeruli in ventral and dorsal positions of the $\mathrm{OB}$, we examined the axonal coalescence of OSNs expressing the ORs MOR28 (ventral side) and mOR-EG (dorsal side). The glomerular position of MOR28, but not of mOR-EG, is greatly influenced by the disruption of Neuropilin-2 or Plexin-A3 (Takeuchi et al., 2010). The disruption of BIG-2 impairs the axonal coalescence of MOR28 and mOR-EG OSNs to different degrees (Kaneko-Goto et al., 2008). Immunostaining with ORspecific antibodies showed increased numbers of glomeruli in the OSNs at P30 in the $P c d h$ - $\alpha$-deficient $\left(P c d h a^{\Delta C R / \triangle C R}\right)$ vs. wildtype (WT) mice, for mOR-EG (averages, lateral 1.6 vs. 1.0; medial 1.4 vs. 1.0 , respectively) and MOR28 (lateral 2.4 vs. 1.2 ; medial 1.3 vs. 1.0) (Table 1, Figure 1A), similar to the previous results for M71, M72, and MOR23 (Hasegawa et al., 2008).

The organization and projections of axons expressing the OR P2 are well-studied; P2 OSNs possess distinct characteristics from other OR-expressing OSNs, such as a lower sensitivity to the loss of neural activity (Lin et al., 2000; Zheng et al., 2000) and a distinct zonal distribution within the OE. Therefore, we next examined the P2 glomeruli in WT and $P c d h$ - $\alpha$-deficient $\left(P c d h a^{\triangle C R / \triangle C R}\right.$ and $P c d h a^{\triangle C R 2 / \triangle C R 2}$ ) mice with a P2-IREStaulacZ locus. As seen for the other ORs, the number of P2 glomeruli increased in the $P c d h$ - $\alpha$-deficient mice (Figure 1B). In whole-mount preparations, the lateral half-bulb showed a mean of 1.9 labeled glomeruli in WT mice ( $n=16$ half-bulbs), and 4.0 glomeruli in the Pcdh- $\alpha$-deficient mice $(n=20$ halfbulbs). In the medial half-bulb, there were 2.1 glomeruli in the WT ( $n=17$ half-bulbs), and 4.1 glomeruli in the $P c d h-\alpha-$ deficient mice ( $n=20$ half-bulbs) (Table 1). Thus, all the homotypic OSNs examined showed a similar phenotype of increased ectopic glomeruli in $P c d h$ - $\alpha$-deficient mice. These results suggested that Pcdh- $\alpha$ 's function contributes to axonal coalescence and the elimination of ectopic glomeruli for all kinds of homotypic OSNs.

\section{GLOMERULAR FORMATION IN Pcdh- $\alpha$ MUTANT MICE AT LATE-EMBRYONIC AND NEONATAL STAGES}

As described above, the Pcdh- $\alpha$-deficient mice had multiple, small, extraneous glomeruli for all the OSN axons examined. These ectopic glomeruli persist until adulthood (Hasegawa et al.,

Table 1 | Number of glomeruli per half-bulb in sectional analysis.

\begin{tabular}{|c|c|c|c|c|c|c|c|}
\hline & Age & $(n)$ & Lateral & (Min-Max) & $(n)$ & Medial & (Min-Max) \\
\hline \multicolumn{8}{|c|}{$10 \mu \mathrm{M}$-THICK SECTION } \\
\hline mOR-EG & P30 & & & & & & \\
\hline$\Delta \mathrm{CR} / \Delta \mathrm{CR}$ & & (10) & 1.6 & $(1.0-4.0) P=0.0301$ & (09) & 1.4 & $(1.0-2.0) P=0.0139$ \\
\hline MOR28 & P30 & & & & & & \\
\hline \multicolumn{8}{|c|}{$50 \mu \mathrm{M}$-THICK SECTION } \\
\hline $\mathrm{P} 2$ & P30 & & & & & & \\
\hline WT & & (16) & 1.9 & $(1.0-3.0)$ & (17) & 2.1 & $(1.0-4.0)$ \\
\hline$\Delta \mathrm{CR} / \Delta \mathrm{CR}$ & & (20) & 4.0 & $(3.0-6.0) P<0.0001$ & (20) & 4.1 & $(2.0-6.0) P<0.0001$ \\
\hline P2 & P30 & & & & & & \\
\hline$\Delta \mathrm{CR} 2 / \Delta \mathrm{CR} 2$ & & (12) & 2.0 & $(1.0-3.0) P=0.0099$ & (12) & 1.6 & $(1.0-3.0) P=0.0059$ \\
\hline
\end{tabular}

$n=$ half-bulb, Mann-Whitney U-test. 


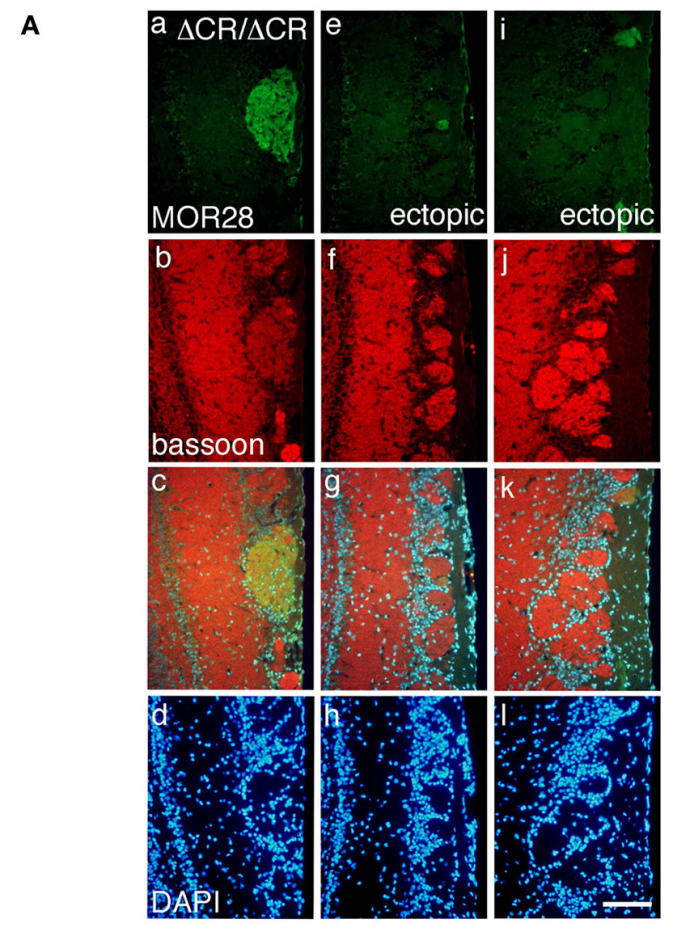

B

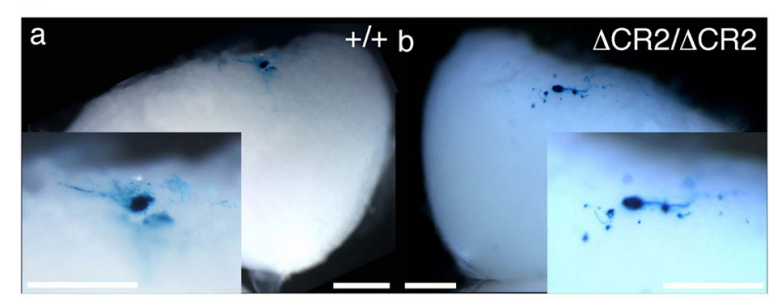

FIGURE 1 | Ectopic glomeruli in MOR28 and P2 OSN projections.

(A) Representative examples of the lateral side of three MOR28 glomeruli, (a: one innate glomerulus, e and i: two small ectopic glomeruli). (b, f, and j) Immunoreactivity for bassoon (a presynaptic active-zone protein) was observed in all the MOR28 glomeruli in the Pcdha ${ }^{\Delta C R / \Delta C R}$ mice. (c, g, and k) merged images. (d, h, and I) DAPI. Scale bar, $100 \mu \mathrm{m}$. (B) Lateral P2 glomeruli in whole-mount OBs from WT (a) and $P c d h a^{\Delta C R 2 / \triangle C R 2}$ (b) mice at P7. In the Pcdha ${ }^{\Delta C R 2 / \triangle C R 2}$ mice, small ectopic glomeruli were observed near the large main glomerulus. Scale bars, $500 \mu \mathrm{m}$.

2008). To determine whether the abnormalities in the Pcdh- $\alpha$ deficient olfactory system resulted primarily from an inability of homotypic OSN axons to coalesce, we next analyzed the formation of glomeruli during early development using mice from crosses between M71-IRES-taulacZ or P2-IRES-taulacZ and WT or $P c d h a^{\triangle C R / \triangle C R}$ mice (Hasegawa et al., 2008). The glomerular structures are initiated on embryonic day (E) 15-16, when both OSN fibers and mitral cell dendrites contribute to the formation of glomerulus-like structures (Blanchart et al., 2006). In the $P c d h a^{\triangle C R / \triangle C R}$ mice, we observed some stray marked fibers that projected to inappropriate regions distant from the target site, and many more M71 and P2 glomerulus-like structures than in WT mice, even on postnatal day 0 (P0) (arrowheads in Figures 2A, 3A).

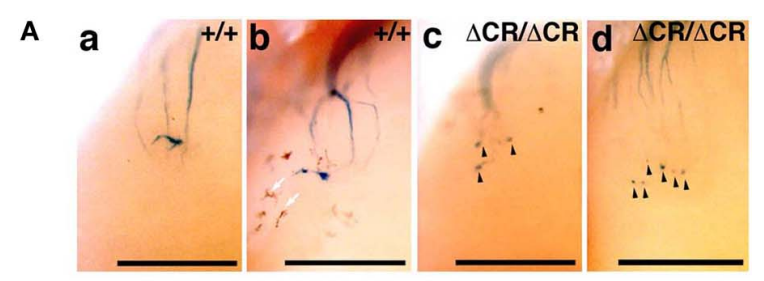

B

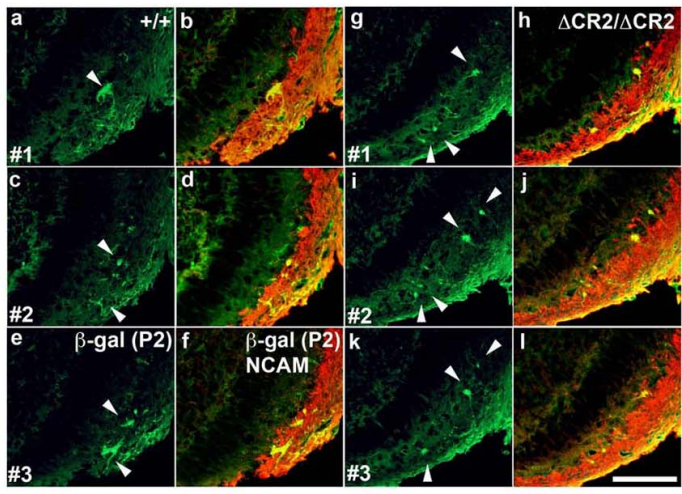

C

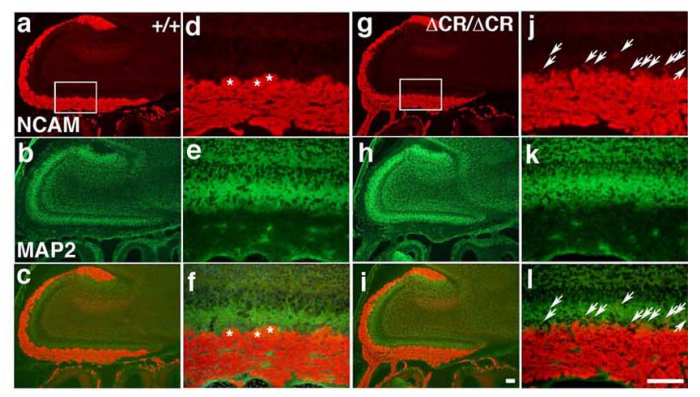

FIGURE 2 | Abnormal glomerular morphology in prenatal and neonata

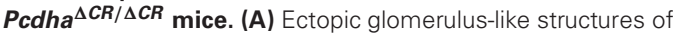
M71-expressing OSNs were found in neonatal $P C d h a^{\Delta C R / \Delta C R}$ mice by whole-mount observation. X-gal-stained lateral M71 glomeruli in whole-mounted OBs from WT (a, b) or PCdha $a^{\Delta C R / \Delta C R}(\triangle C R / \Delta C R)(\mathrm{c}, \mathrm{d})$ mice at P0. In PCdha ${ }^{\triangle C R / \triangle C R}$ mice, abnormal axonal projections from the olfactory nerve were often detected (arrowheads). Melanocytes (arrows) were visible on some of the whole-mount preparations of the olfactory bulbs. Scale bars, $500 \mu \mathrm{m}$. (B) Sectional analysis of the coalescence of WT (a-f) and PCdha ${ }^{\Delta C R 2 / \triangle C R 2}$ (g-l) P2 axons on embryonic day (E) 17.5. Serial sections of OBs were double-labeled with anti- $\beta$-galactosidase (for P2, green) and anti-NCAM (red) antibodies. There were more P2

glomerulus-like structures (arrowheads) in the PCdha ${ }^{\Delta C R 2 / \triangle C R 2}$ $(\triangle C R 2 / \triangle C R 2)$ mice (See Figure 3A). Scale bar, $100 \mu \mathrm{m}$. (C) OBs in WT $(\mathrm{a}-\mathrm{c})$ and $P C d h a^{\triangle C R / \triangle C R}$ mice (g-i) were double-labeled with anti-NCAM (red) and anti-MAP2 (green) antibodies. Due to the orientation shown in panels (d) and (j), in $P C d h a^{\triangle C R / \triangle C R}$ mice, the OSN axons appeared to extend beyond the normal confines of the glomerular layer and often terminated as an intensely stained spatially restricted and condensed structure ( $\mathrm{j}$ and $\mathrm{l}$, arrows). In addition, the primary axons terminated in less clearly defined glomeruli in $P c d h a^{\Delta C R / \triangle C R}(\triangle C R / \Delta C R)$ than in WT $(+/+)$ mice. Primary glomerular structures could be detected in WT $(d, f$, asterisks) but not $P C d h a^{\triangle C R / \triangle C R}$ mice $(j, l)$ (See Figures $6 \mathbf{B}, \mathbf{C}$ ).

Immunostaining with anti-MAP2 (green) antibody did not show significant differences between WT (e) and $P c d h a^{\Delta C R / \Delta C R}(\mathrm{k})$ mice. Scale bar, $100 \mu \mathrm{m}$.

Sectional analysis of the OBs on E17.5 clearly showed the abnormal coalescence of P2 axons-multiple small and extraneous P2 glomerular-like structures-during the early formation of glomeruli (Figure 2B). These results indicated that 


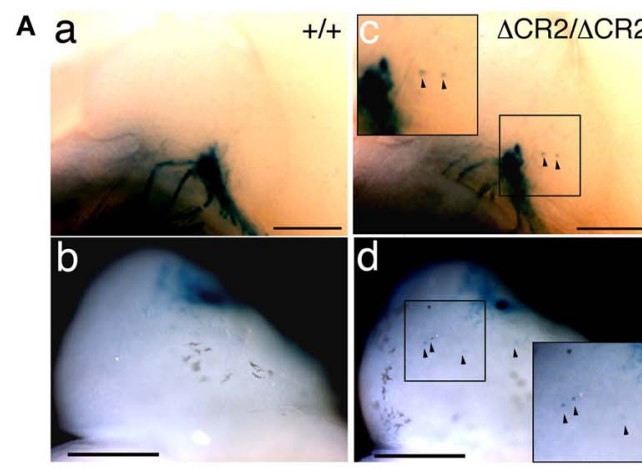

B

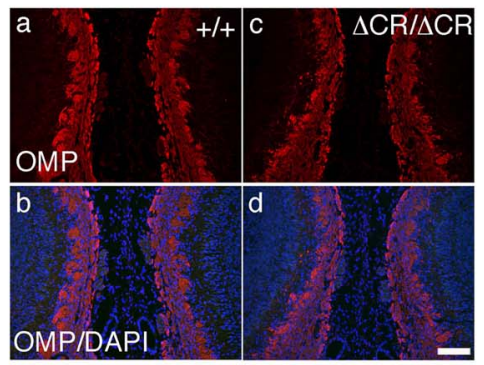

C
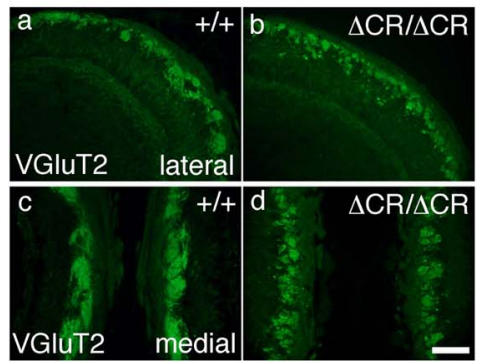

FIGURE 3 | Ectopic glomerulus-like structures of P2-expressing OSNs in neonatal Pcdha ${ }^{\Delta C R 2 / \Delta C R 2}$ mice found by whole-mount observation. (A) X-gal-stained P2 glomeruli in the PO OBs of WT $(a, b)$ or PCdha ${ }^{\triangle C R 2 / \triangle C R 2}$ (c, d) mice. In PCdha ${ }^{\Delta C R 2 / \triangle C R 2}$ mice, abnormal axonal projections from the olfactory nerve were often detected (arrowheads). Scale bars, $500 \mu \mathrm{m}$. (B) Double staining with an anti-OMP antibody and DAPI in the PO OBs in coronal sections of WT $(\mathrm{a}, \mathrm{b})$ or $P c d h a^{\Delta C R / \triangle C R}$ (c, d) mice. Scale bar, $100 \mu \mathrm{m}$. (C) Immunostaining with an anti-VGluT2 antibody in the lateral $(a, b)$ and medial $(c, d)$ sides of the PO OBs in WT $(a, c)$ or $P C d h a^{\Delta C R / \triangle C R}(\mathrm{~b}, \mathrm{~d})$ mice. Scale bar, $100 \mu \mathrm{m}$.

the ectopic glomeruli found in the $P c d h a^{\Delta C R / \triangle C R}$ mice, which were often maintained until adulthood, were derived from the late-embryonic stage before birth, suggesting that Pcdh- $\alpha$ is involved in the initial axonal coalescence of the homotypic OSNs as well as the elimination of ectopic glomeruli during postnatal development. Ebrahimi and Chess (2000) showed that the successful coalescence of OSN axons at adulthood depends on the population size of OSNs (more OSNs result in better coalescence). On the other hand, small ectopic glomeruli that appear in normal newborn mice completely disappear by adulthood.

To analyze the dendrites of bulb neurons and OSN axons in more detail, we performed immunostaining for NCAM, an axonal marker and for MAP-2, a dendritic marker. In WT mice at P0, the outline of individual glomeruli surrounded by periglomerular cells could be recognized in the glomerular layer by NCAM staining (asterisks in Figure 2C d, f). In contrast, such glomerular structures were not seen in $P c d h a^{\Delta C R / \triangle C R}$ mice, in which NCAM-positive axons from the OSNs were often found in the external plexiform layer (arrows in Figure 2C j, l). These abnormal axonal clusters were confirmed by immunostaining with anti-OMP, a marker of OSNs and with anti-VGluT2, a presynaptic marker (Figures 3B,C). These results suggested that abnormal axonal coalescence was a common feature of all the homotypic ONSs in the $P c d h a^{\triangle C R / \triangle C R}$ mice. These observations support the idea that Pcdh- $\alpha$ helps to determine the precise organization of homotypic OSN axon projections during all developmental stages.

\section{DIFFERENTIAL EXPRESSION OF EACH Pcdh- $\alpha$ ISOFORM IN SINGLE NEURONS INCLUDING OSNs}

$P c d h-\alpha$ mRNAs are extensively expressed in almost all of the OSNs from E11.5 to adulthood, and Pcdh- $\alpha$ proteins are enriched in the OSN axons and their terminals in the glomeruli (Hasegawa et al., 2008). However, the mechanisms by which the diverse Pcdh$\alpha$ family contributes to the axonal coalescence into glomeruli remain unclear. To address this issue, we examined the expression pattern of various $P c d h-\alpha$ isoforms in the OSNs. First, in situ hybridization histochemistry with probes for isoformspecific $\alpha 11$ and isoform-common $\alpha C R$ was performed for the OSNs of the OE. Extensive staining was observed at E16.5 for both the $\alpha 11$ and $\alpha C R$ probes (Figure $4 \mathrm{~A}$ a, b). At P56, their expressions were widely observed in the $\mathrm{OE}$, and appeared in both the immature and mature OSN cell body layers but not in the sustentacular or basal cell layers (Figure $4 \mathrm{~A} \mathrm{c}, \mathrm{d}$ ). In contrast to the $\alpha C R$ probe, the isoform-specific $\alpha 11$ probe showed a mosaic staining pattern (Figure $4 \mathrm{~A}$ e). Similar mosaic patterns were observed with other $\alpha$ isoform-specific probes (data not shown, and see $\alpha 1$ in Figure 6E). The differential expression of $P c d h-\alpha$ isoforms in single neurons is also observed in periglomerular cells (Kohmura et al., 1998) and mitral/tufted cells (data not shown) in the OB. These results suggested that individual OSNs and neurons in the $\mathrm{OB}$ differentially express $P c d h-\alpha$ isoforms, similar to Purkinje cells (Esumi et al., 2005).

A previous single-cell RT-PCR analysis of Purkinje cells revealed strong evidence for the stochastic and combinatorial expression of $P c d h-\alpha$ isoforms in individual neurons (Esumi et al., 2005). We therefore performed single-cell RT-PCR analysis of the OSNs to determine the expression pattern of Pcdh$\alpha$ isoforms in these neurons at the single-cell level. Using OMP-GFP mice, we picked up GFP-positive cells. Of 30 GFPpositive OSNs, 18 were OMP positive and also had a product representing at least one of the $12 P c d h-\alpha$ variable isoforms (Figure 4B). Each single OSN expressed a different combination of $P c d h-\alpha$ isoforms, except for four $\alpha 2$-positive and two $\alpha 4$-positive cells. Although this one-tube single-cell RT-PCR method has more experimental limitations than the split singlecell RT-PCR method, these results indicated that individual OSNs differentially express $P c d h-\alpha$ isoforms, similar to Purkinje cells. 


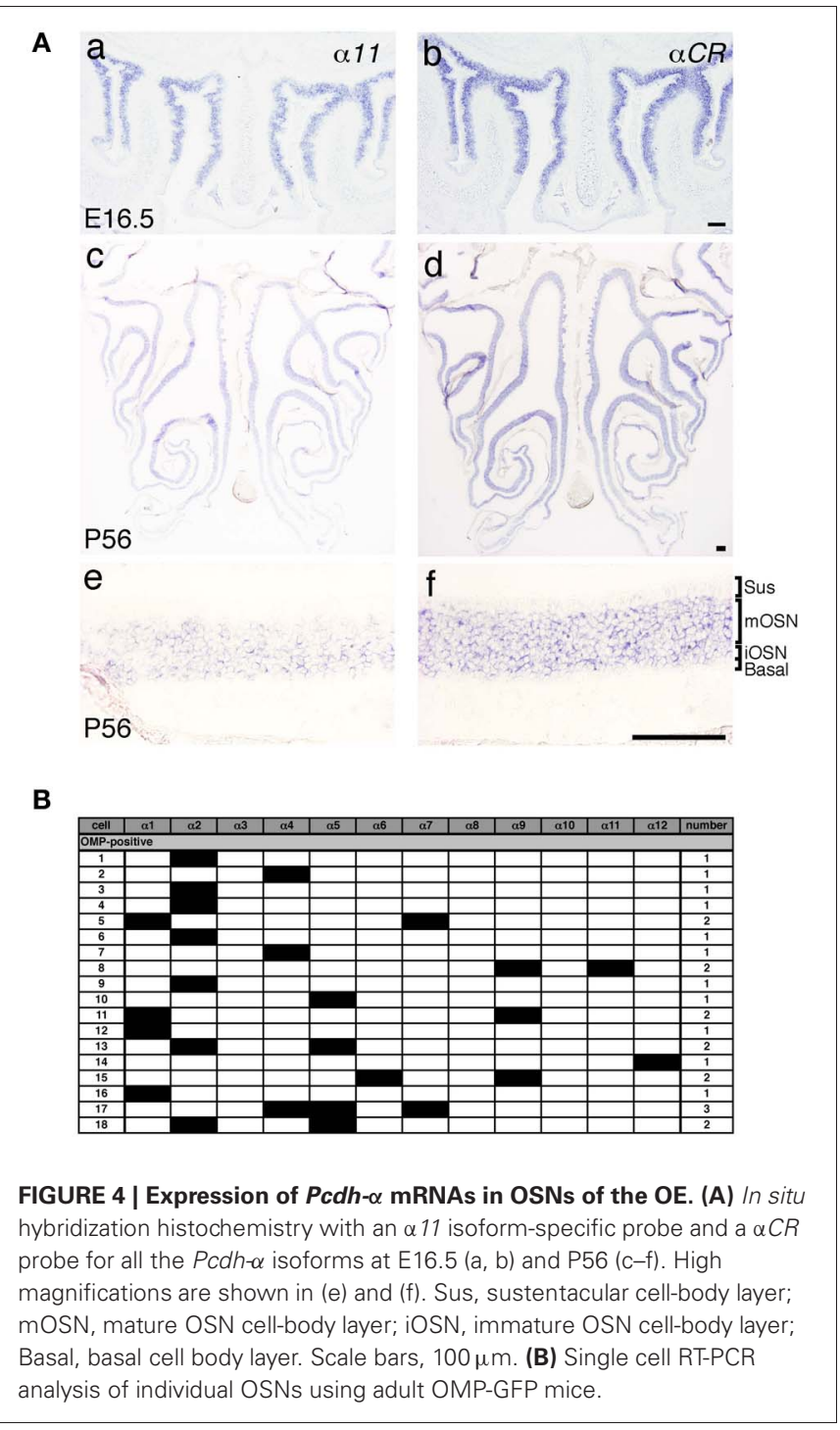

\section{AXONAL COALESCENCE IN MUTANT MICE IN WHICH THE $\alpha 2$ TO $\alpha$ C2 EXONS IN THE VARIABLE REGION OF THE Pcdh- $\alpha$ CLUSTER ARE DELETED}

Our findings indicated that $\mathrm{Pcdh}-\alpha$ proteins are essential for the homotypic axonal coalescence of OSNs; however, it was not known whether all or some specific $\mathrm{Pcdh}-\alpha$ isoforms were necessary for this coalescence. To address this question, we produced and analyzed a $P c d h-\alpha$ variable exon-deletion mutant line: $P c d h a^{\Delta(2-c 2) / \Delta(2-c 2)}$ mice (Figure 5), in which the $\alpha 2-\alpha c 2$ exons were deleted, and only $\alpha 1$ remained, in the variable region of the $P c d h-\alpha$ cluster (Figure 6A). In the $P c d h a^{\Delta(2-c 2) / \Delta(2-c 2)}$ mice, the remaining $\alpha 1$ isoform was highly expressed in the brain (Figure 6B). The expression level of the $\alpha 1$ gene in the $P c d h a^{\Delta(2-c 2) / \Delta(2-c 2)}$ mouse brain increased by approximately 70 folds compared to WT (Figure 6C), while the total level of $P c d h-\alpha$ expression detected by the common cytoplasmic region was similar between the $P c d h a^{\Delta(2-c 2) / \Delta(2-c 2)}$ and WT mice. In immunoblots of brain extract samples, broad bands were immunostained by an anti-Pcdh- $\alpha$ CR antibody (Murata et al.,
2004) that recognized a common cytoplasmic region of Pcdh$\alpha$ isoforms in WT mice; in contrast, a sharp band was strongly stained in the Pcdha $a^{\Delta(2-c 2) / \Delta(2-c 2)}$ mice (Figure 6D). We previously reported that in deletion mutants of the variable region of the Pcdh- $\alpha$ cluster, the missing exons are efficiently compensated for by the remaining variable exons (Noguchi et al., 2009). Therefore, to examine the compensation of $P c d h-\alpha$ expression by the remaining $\alpha 1$ gene in the OSNs of $P c d h a^{\Delta(2-c 2) / \Delta(2-c 2)}$ mice, we performed in situ hybridization analysis of the OE of WT and $P c d h a^{\Delta(2-c 2) / \Delta(2-c 2)}$ mice with $\alpha 1$ and $\alpha C R$ probes (Figure 6E). Interestingly all the OSNs in the OE of $P c d h a^{\Delta(2-c 2) / \Delta(2-c 2)}$ mice extensively expressed the $\alpha 1$ isoform similar to that of $\alpha C R$, while the OSNs of WT mice rarely expressed $\alpha 1$. However, the expression pattern and level of the total $P c d h-\alpha$ isoforms detected with the $\alpha C R$ probe were not markedly changed (Figure 6E). Immunostaining with the anti-Pcdh- $\alpha$ CR antibody also showed that the distribution pattern and level of the Pcdh- $\alpha$ proteins were not markedly different between the WT and $P c d h a^{\Delta(2-c 2) / \Delta(2-c 2)}$ mice (Figure 6F). In $P c d h a^{\Delta(2-c 2) / \Delta(2-c 2)}$ mice, the $\alpha 1$ protein was extensively distributed throughout the OSN axons and glomeruli. These results indicated that the $\alpha 1$ isoform completely compensated for the expression of the other $P c d h-\alpha$ isoforms in all the OSNs and neurons of the OBs.

We next examined the axonal coalescence of homotypic OSNs of the $P c d h a^{\Delta(2-c 2) / \Delta(2-c 2)}$ mice. We crossed the $P c d h a^{\Delta(2-c 2) / \Delta(2-c 2)}$ mice with M71-IRES-taulacZ or MOR23IRES-taulacZ mice. In whole-mount $O B$ preparations of M71-IRES-taulacZ or MOR23-IRES-taulacZ mice at P30, there was typically one labeled glomerulus per half-bulb at the lateral and medial side in both WT and $P c d h a^{\Delta(2-c 2) / \Delta(2-c 2)}$ mice (Table 2) (Figure 7A). Sectional analyses of the MOR23 glomeruli showed that the average number of glomeruli in both the lateral and medial sides of the half-bulbs were not significantly different between the WT and $P c d h a^{\Delta(2-c 2) / \Delta(2-c 2)}$ mice (Table 2). Whole-mount analyses of the M71 glomeruli also showed no significant difference between the WT and $P c d h a^{\Delta(2-c 2) / \Delta(2-c 2)}$ mice in the average number of glomeluli in both the lateral and medial sides of the half-bulbs (Table 2). The coalescence of M71 and MOR23 axons appeared normal in the $P c d h a^{\Delta(2-c 2) / \Delta(2-c 2)}$ mice, in which the $\alpha 1$ protein was extensively enriched in all the OSN axons and glomeruli (Figure 7B). In addition, immunostaining of adjacent sections with the antiPcdh $\alpha$ CR antibody revealed that the $\alpha 1$ protein was distributed in both the lateral M71 and medial MOR23 glomeruli of the $\mathrm{OB}$ in the $P c d h a^{\Delta(2-c 2) / \Delta(2-c 2)}$ mice (Figure 7B). These results indicated that a diversity of Pcdh- $\alpha$ isoforms in OSNs is not always required for the axonal coalescence of M71 and MOR23 homotypic OSNs into glomeruli. Instead, constitutive expression of the $\alpha 1$ isoform in neurons including OSNs was sufficient for the normal coalescence and elimination of OSN projections.

\section{REOUIREMENT OF THE COMMON CYTOPLASMIC REGION OF Pcdh- $\alpha$ PROTEINS FOR THE NORMAL COALESCENCE AND ELIMINATION OF ECTOPIC OSN PROJECTIONS IN GLOMERULI}

$P c d h a^{\triangle C R / \triangle C R}$ mice are presumptive null mutants of the $P c d h$ $\alpha$ locus; no Pcdh- $\alpha$ proteins are seen in the brain of these mice (Hasegawa et al., 2008). Another Pcdh- $\alpha$ mutant mouse, 
A G16Neo allele

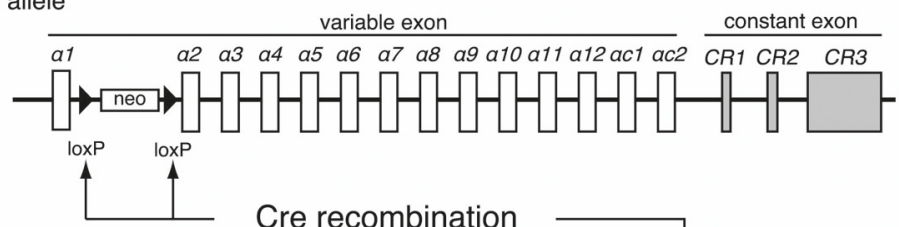

G1 loxP allele

variable exon $\frac{\text { constant exon }}{\text { CR1 CR2 CR3 }}$ a1 $\quad$ a2 $a 3$ a4 a5 a6 a7 a8 a9 a10 a11 a12 ac1 ac2

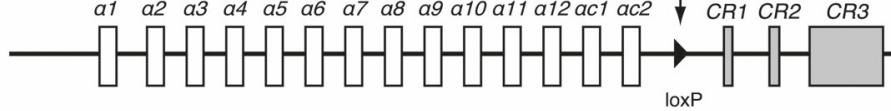

Pcdha $\Delta$ (2-c2)allele

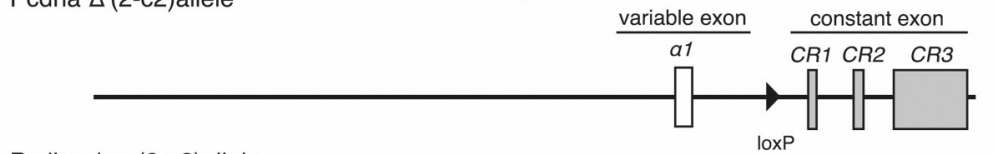

Pcdha dup (2-c2)allele

variable exon constant exon

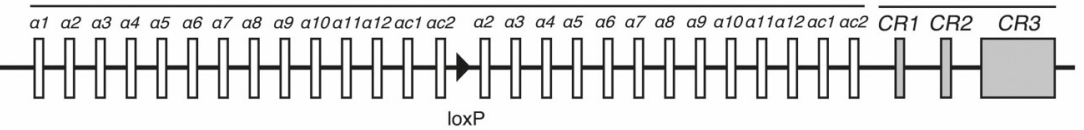

B Wild-type allele

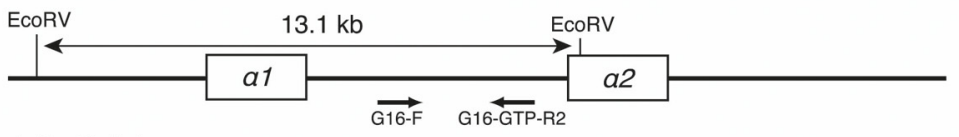

Pcdha $\Delta$ (2-c2)allele

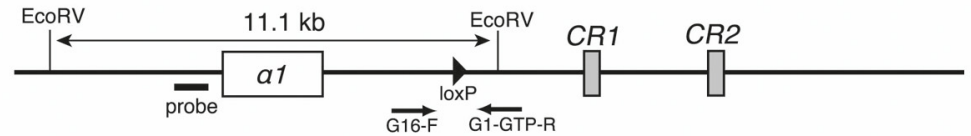

C

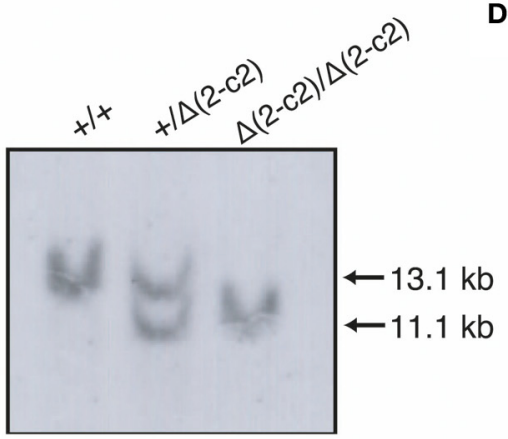

D

FIGURE 5 | Generation of the $\boldsymbol{P c d h} a^{\Delta(2-c 2)}$ and $\boldsymbol{P c d h a d u p ( 2 - c 2 )}$ alleles in mice. (A) $P c d h a^{\Delta(2-c 2)}$ and $P c d h a^{d u p(2-c 2)}$ mice were generated by mating G16Neo mice, G1 loxP mice, and Sycp-Cre transgenic mice created by synaptosomal-Cre (TAMERE) system in the testis. This Cre is expressed during meiotic crossing-over. (B) Partial genomic structures of the WT and $P_{c d h} a^{\Delta(2-c 2)}$ allele. (C,D) Genotyping of WT $(+/+)$, Pcdha ${ }^{+/ \Delta(2-c 2)}[+/ \Delta$ $(2-c 2)]$, and $P c d h a^{\Delta(2-c 2) / \Delta(2-c 2)}[\Delta 2-c 2 / \Delta(2-c 2)]$ by Southern blot and PCR analyses (see "Materials and Methods").
$P c d h a^{\Delta A / \Delta A}$, lacks the common cytoplasmic region (56 amino acids) of Pcdh- $\alpha$ A-type isoforms, and expresses a truncated Pcdh- $\alpha$ protein that lacks the A-type specific cytoplasmic tail (Katori et al., 2009). Pcdha ${ }^{\Delta A / \Delta A}$ mice show disrupted and diffuse serotonergic axon projections, similar to those of the
$P c d h a^{\triangle C R / \triangle C R}$ mice (Katori et al., 2009). To further address how the Pcdh- $\alpha$ proteins control the axonal coalescence of homotypic OSNs expressing specific ORs, we analyzed the axonal coalescence in $P c d h a^{\triangle A / \triangle A}$ mice with the M71-IRES-taulacZ locus. We found a perturbed coalescence of M71 axons in the $P c d h a^{\Delta A / \Delta A}$ mice at 
A Wild-type allele

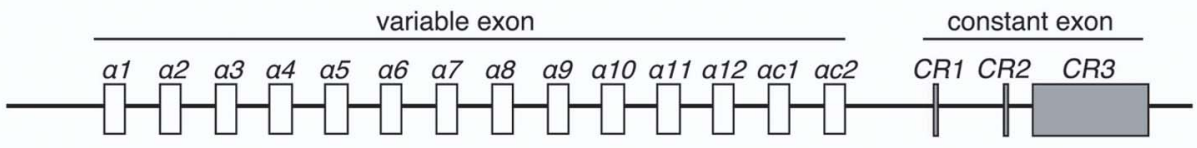

Pcdha $\Delta(2-c 2)$ allele
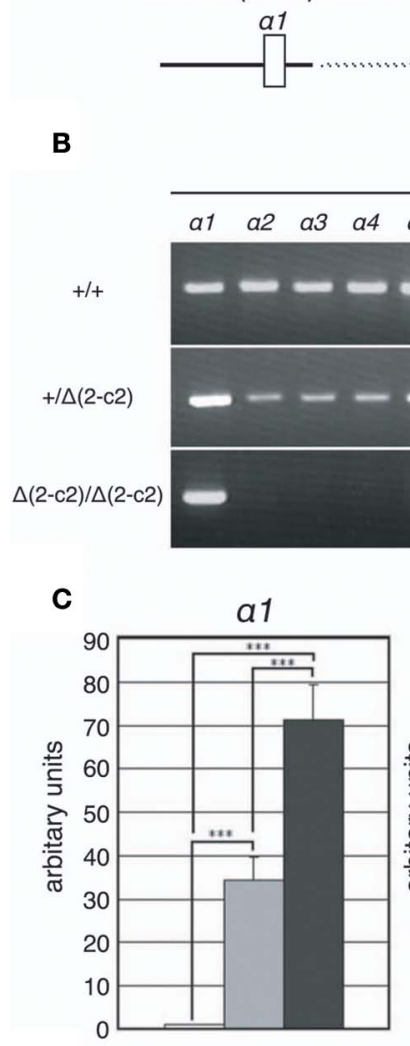

E
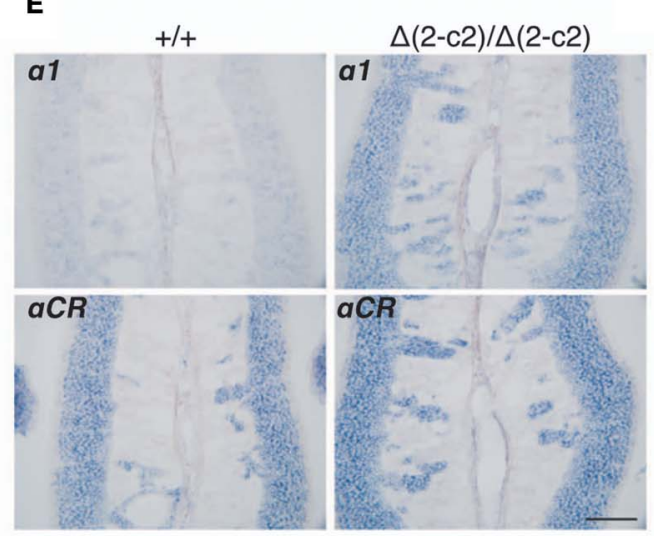

FIGURE 6 | Pcdha ${ }^{\Delta(2-c 2) / \Delta(2-c 2)}$ deletion mutant mice. (A) Wild-type Pcdh-a genes consist of variable-region ( $\alpha 1$ to $\alpha 12, \alpha c 1$ and $\alpha c 2$ ) and constant-region (CR1-CR3) exons. The individual variable exons are transcribed from their own promoters. A Pcdh- $\alpha$ transcript is produced from one variable exon and three or four constant exons by splicing. In the $P c d h a^{\Delta(2-c 2) / \Delta(2-c 2)}$ mice, exons $\alpha 2-\alpha c 2$ were deleted, leaving only exon $\alpha 1$ in the variable region. (B) RT-PCR analysis of brain extracts of WT $(+/+), P c d h a^{+/ \Delta(2-c 2)}[+/ \Delta(2-c 2)]$, and $P c d h a^{\Delta(2-c 2) / \Delta(2-c 2)} \Delta(2-c 2 / \Delta 2-c 2)$ mice. (C) qRT-PCR analysis of $\alpha 1$ transcripts in the brain of WT $(+/+), P c d h a^{+/ \Delta(2-c 2)}[+/ \Delta(2-c 2)]$, and

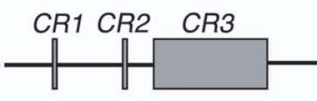

D

Pcdh-a

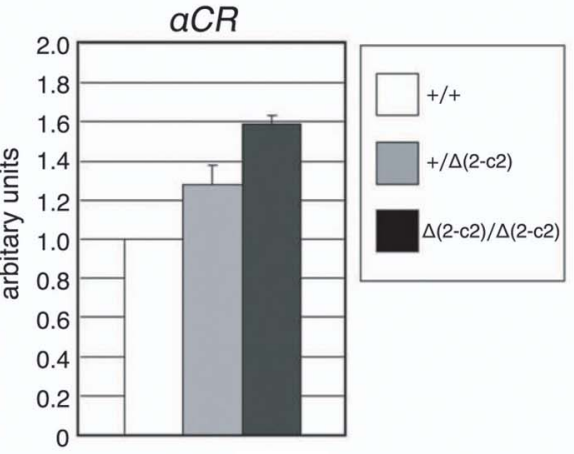

$\mathbf{F}$
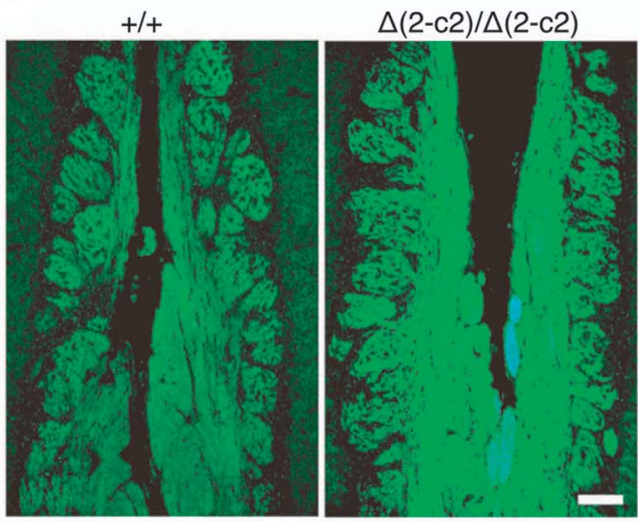

$P c d h a^{\Delta(2-c 2) / \Delta(2-c 2)}[\Delta(2-c 2) / \Delta(2-c 2)]$ mice. ${ }^{* * *} P<0.0001$, vs. WT and vs. $P c d h a^{+/ \Delta(2-c 2)}$. Data are shown as the mean \pm S.D. (D) Immunoblotting analysis of brain lysates with an anti-Pcdh $\alpha \mathrm{CR}$ antibody. (E) Expression of $\alpha 1$ and $\alpha C R$ transcripts in OSNs of the OE were examined by in situ hybridization histochemistry. Constitutive expression of $\alpha 1$ transcripts was seen in the OSNs of $P c d h a^{\Delta(2-c 2) / \Delta(2-c 2)}[\Delta(2-c 2) / \Delta(2-c 2)]$ mice. Scale bar, $100 \mu \mathrm{m}$. (F) Pcdh- $\alpha$ immunoreactivity with an anti-Pcdh $\alpha$ CR antibody was strong in the OSN axons and glomeruli of both WT $(+/+)$ and $P c d h a^{\Delta(2-c 2) / \Delta(2-c 2)}$ $[\Delta(2-c 2) / \Delta(2-c 2)]$ mice. Scale bar, $100 \mu \mathrm{m}$. 
Table 2 | Number of glomeruli per half-bulb.

\begin{tabular}{|c|c|c|c|c|c|c|c|}
\hline & Age & $(n)$ & Lateral & (Min-Max) & $(n)$ & Medial & (Min-Max) \\
\hline MOR23 & P30 & & & & & & \\
\hline$\Delta(2-c 2) / \Delta(2-c 2)$ & & (16) & 1.0 & $(-1)$ & (16) & 1.1 & $(1.0-2.0) P=0.2120$ \\
\hline \multicolumn{8}{|l|}{ WHOLE-MOUNT } \\
\hline$\Delta(2-c 2) / \Delta(2-c 2)$ & & (16) & 1.7 & $(1.0-3.0) P=0.4620$ & (16) & 1.1 & $(1.0-2.0) P=0.0191$ \\
\hline M71 & P30 & & & & & & \\
\hline WT & & (10) & 1.2 & $(1.0-2.0)$ & (10) & 1.1 & $(1.0-2.0)$ \\
\hline$\Delta \mathrm{A} / \Delta \mathrm{A}$ & & (10) & 2.1 & $(1.0-3.0) P=0.0150$ & (10) & 1.6 & $(1.0-2.0) P=0.0223$ \\
\hline
\end{tabular}

$n=$ half-bulb, Mann-Whitney U-test
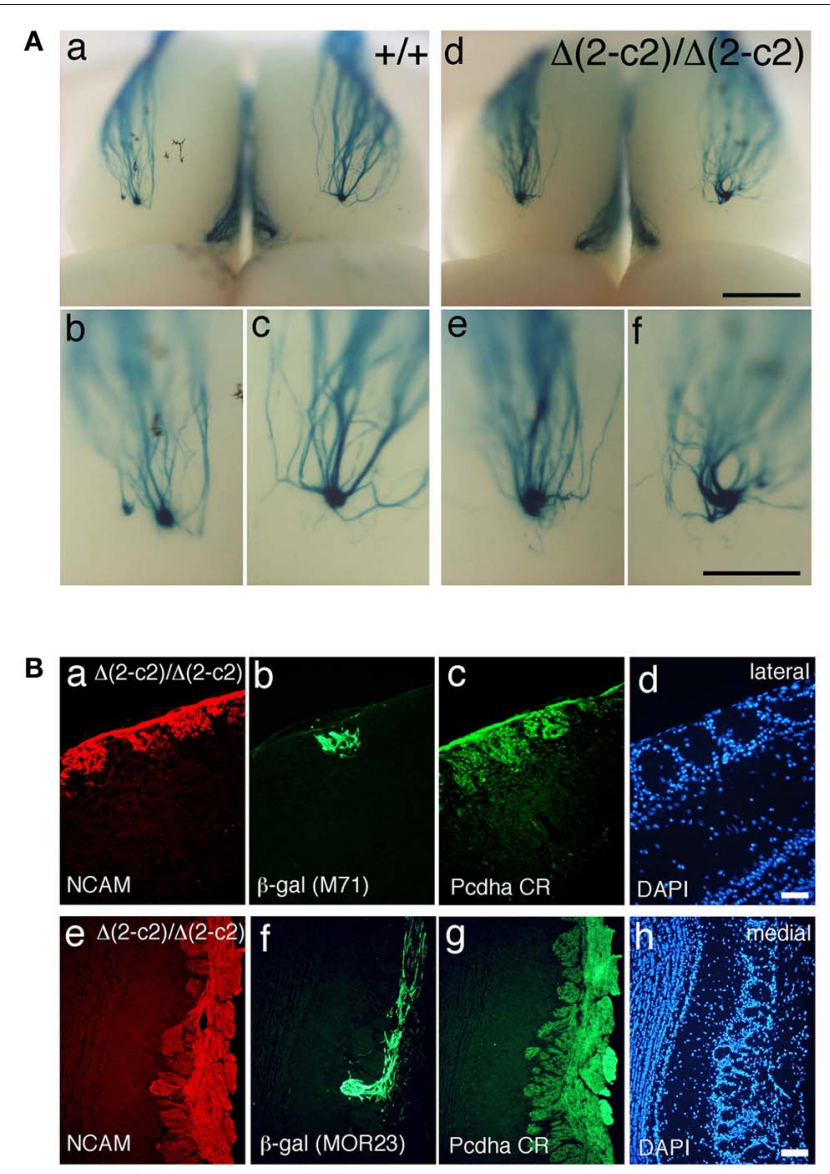

FIGURE 7 | Axonal coalescence of OSN projections in

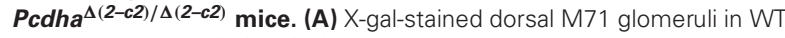
$(+/+)$ and $P c d h a^{\Delta(2-c 2) / \Delta(2-c 2)}(\Delta(2-c 2) / \Delta(2-c 2))$ mice at P30. Glomeruli appeared normal in the $P c d h a^{\Delta(2-c 2) / \Delta(2-c 2)}$ mice. Scale bars, $1 \mathrm{~mm}$ for panels (a, d), and $500 \mu \mathrm{m}$ for panels (b, c, e, and f). (B) Analysis of M71 (b) and MOR23 (f) glomeruli in the Pcdha $a^{\Delta(2-c 2) / \Delta(2-c 2)}$ mice. Sections of OBs were double-labeled with $\beta$-galactosidase ( $\beta$-gal; green) and NCAM (red) (a, e) antibodies. Each adjacent section (c, d and g, h) was stained with anti-Pcdha CR antibody and 4',6-diamidino-2-phenylindole (DAPI; blue). Scale bars, $50 \mu \mathrm{m}$ for panels (a-d) and $100 \mu \mathrm{m}$ for panels (e-h).
P30 (Figure 8A) and P7 (Figure 8B). Similar abnormalities were found in the $P c d h a^{\triangle C R / \triangle C R}$ mice (Figure 8B, Hasegawa et al., 2008). Whole-mount analysis of the M71-IRES-taulacZ mice typically showed one labeled glomerulus per half-bulb at the lateral and medial side and in rare cases a second glomerulus; thus, there was an average of 1.1-1.2 glomeruli per lateral or medial side of the half-bulb at P30 in WT mice. In contrast, $P c d h a^{\Delta A / \Delta A}$ mice showed a perturbed coalescence of M71 axons and significantly higher numbers of M71 glomeruli compared to WT mice (Table 2). These results indicated that the common cytoplasmic region among $\mathrm{Pcdh}-\alpha$ proteins is required for both the initial coalescence of OSN axons and the elimination of glomeruli during development.

\section{NO EFFECT OF THE NEURAL ACTIVITY OF OSNs ON THE EXPRESSION LEVEL AND DISTRIBUTION PATTERN OF Pcdh- $\alpha$}

Axon guidance molecules showing OR-specific expression are often regulated by the neural activity of OSNs (Serizawa et al., 2006; Kaneko-Goto et al., 2008); therefore, we examined whether a reduction in OSN neural activity would affect the Pcdh- $\alpha$ expression. WT mice were subjected to unilateral naris occlusion at 3 weeks and analyzed by in situ hybridization histochemistry after 1 week. Efficiency of the naris occlusion was validated by the loss of tyrosine hydroxylase ( $\mathrm{TH})$ signals from the glomerular layer on the closed side of the OB (Figure 9A a) (Stone et al., 1990). In contrast, mRNA signals of the isoform common $\alpha C R$ probe in the OE were quite similar between the open and closed sides (Figure 9A b). In the OE, the expression levels with the $\alpha 11$ and $\alpha C R$ probes were quite similar between the open and closed sides (Figure 9A c, d). Furthermore, immunohistochemistry of the P30 WT mouse after naris occlusion showed that the distribution and intensity of Pcdh- $\alpha$ immunoreactivity in the OB were almost the same between the closed and open sides (Figure 9B). These results indicated that the Pcdh- $\alpha$ expression in the OSNs and $\mathrm{OB}$ was not altered by the OSN neural activity.

Naris occlusion leads to sensory deprivation, which might inhibit the neural activity-regulated process by which multiple glomeruli are eliminated. Indeed, a previous study showed that this treatment significantly increases the number of glomeluli (Zou et al., 2004). Therefore, we next analyzed the number 


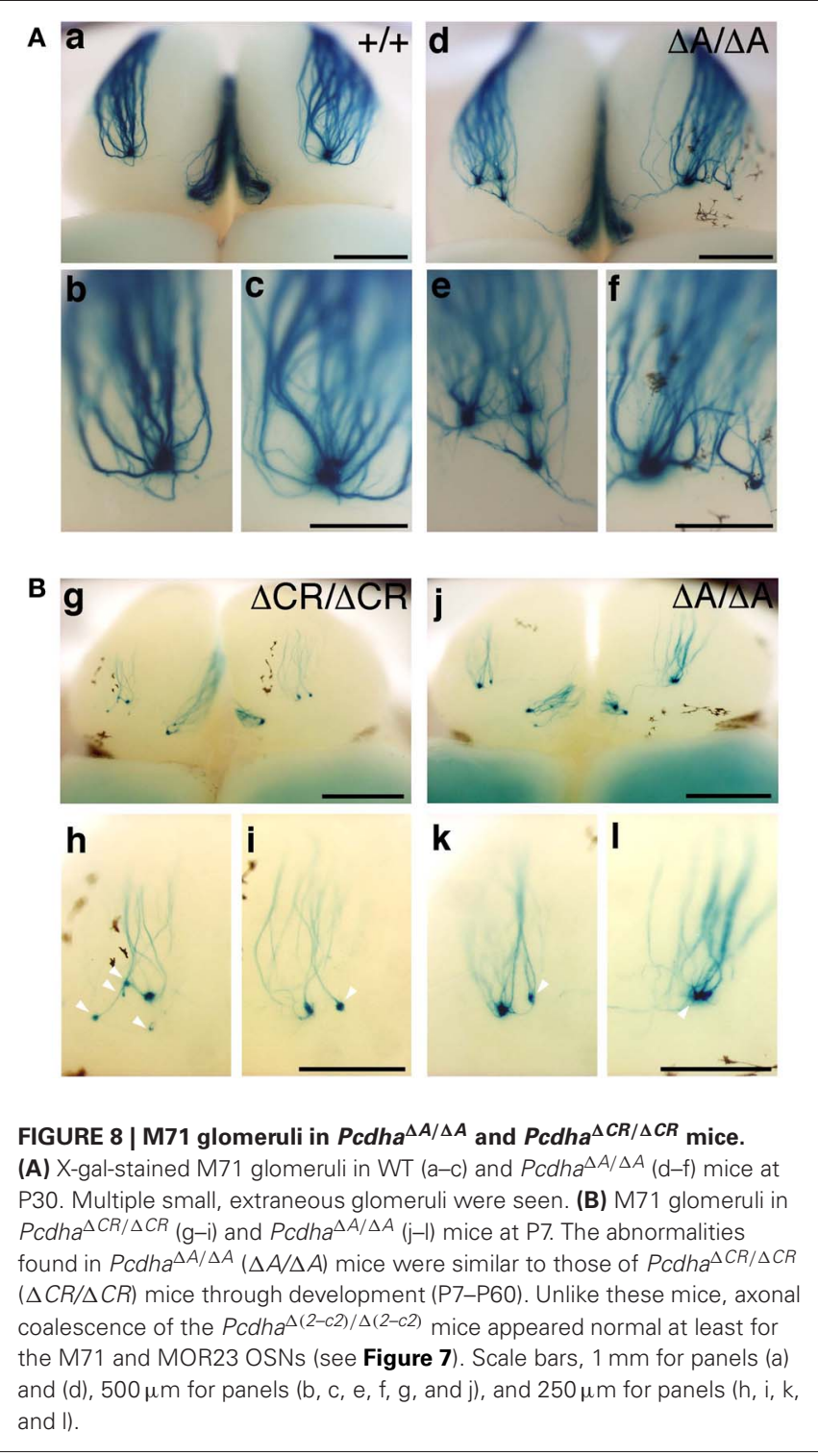

of M71 and MOR23 glomeruli between the closed and open sides of the $\mathrm{OB}$ to examine the effects of naris occlusion in the $P c d h a^{\Delta C R / \triangle C R}$ or $P c d h a^{\Delta C R 2 / \triangle C R 2}$ mice. Although the number of ectopic glomeruli was already significantly increased in these $P c d h$ - $\alpha$-deficient mice, unilateral naris occlusion further increased the number of M71 and MOR23 glomeruli in the WT and $P c d h$ - $\alpha$-deficient $\left(P c d h a^{\Delta C R / \triangle C R}\right.$ and $\left.P c d h a^{\Delta C R 2 / \triangle C R 2}\right)$ mice until they all reached similar levels (Figure 9C). Thus, even in $P c d h-\alpha$-deficient mice, the ectopic glomeruli were further increased by reduced neural activity. Together, these findings further suggest that Pcdh- $\alpha$ proteins function continuously to organize the projections of OSN axons and eliminate ectopic glomeruli in a neural activity-independent manner (Figure 10).

\section{DISCUSSION}

We previously reported that loss of the $\operatorname{Pcdh}-\alpha$ family $\left(P c d h a^{\Delta C R / \triangle C R}\right)$ disrupts the coalescence of OSN axons into glomeruli (Hasegawa et al., 2008). However, the relationship between the diverse Pcdh- $\alpha$ isoforms and axonal coalescence was not well understood. In the present study, we found that Pcdh- $\alpha$ isoform expression and function in the olfactory system are different from those of other known olfactory guidance molecules. First, the phenotypes of axonal coalescence of OSNs in $P c d h-\alpha-$ deficient mice were not restricted to specific OR-expressing OSNs but rather were found in all kinds of homotypic OSNs. Second, the expression of Pcdh- $\alpha$ molecules was not altered by the neural activity of OSNs. Third, following $P c d h-\alpha$ deficiency, the numbers of ectopic glomeruli were even further increased by a reduction in neural activity, suggesting that Pcdh- $\alpha$ 's functions in coalescing and eliminating abnormal OSN axons are not dependent on neural activity. Fourth, the constitutive expression of Pcdh- $\alpha$ protein in neurons including OSNs was essential for normal axonal coalescence, although the diversity of Pcdh- $\alpha$ proteins was not always needed. In addition, we found that a common cytoplasmic region among Pcdh- $\alpha$ proteins was essential for the axonal coalescence and elimination of ectopic glomeruli. Taken together, we conclude that the Pcdh- $\alpha$ family is constitutively involved in mechanisms regulating the coalescence of OSN axons and elimination of small ectopic glomeruli that are independent of OR-specificity and neural activity.

Ebrahimi and Chess (2000) proposed a mechanism for maintaining the axonal coalescence of OSNs, in which the presence of other OSNs expressing the same OR is required, called "interdependence." The projections of OSNs expressing an ectopic OR always coalesce in newborn mice, although this coalescence is not always maintained in adult mice. The probability of maintaining coalescence in adult mice is positively correlated with the number of OSNs expressing the OR (Ebrahimi and Chess, 2000). Thus, there must be some mechanism for removing the excess glomeruli. In the $P c d h$ - $\alpha$-mutant mice, even small glomeruli do not disappear in adulthood. The present data showed that the constitutive expression and cytoplasmic region of Pcdh- $\alpha$ proteins are required for the elimination of miswired axons.

\section{Pcdh- $\alpha$ MOLECULES MAY FUNCTION IN A NEURAL ACTIVITY-INDEPENDENT MANNER}

It has been suggested that neural activity is required for the establishment and maintenance of specific glomeruli (Zou et al., 2004). Blocking the neural activity in OSNs by overexpression of the inward rectifying potassium channel (Kir2.1) induce multiple abnormal glomeruli in P2, MOR28 and MOR23 axons (Yu et al., 2004). On the other hand, in olfactory cyclic nucleotide-gated channel subunit 1 (OCNC1)-deficient mice, M72 axons form multiple abnormal glomeruli, but $\mathrm{P} 2$ axons do not (Lin et al., 2000; Zheng et al., 2000). Thus, P2 axons are probably less affected by a reduction in neural activity than other axon types in determining their targeted projections to the OB.

Interestingly, the $P c d h$ - $\alpha$-deficient mice in our present study clearly showed abnormal multiple glomeruli in all OR-expressing OSNs examined, even in the P2 axons. Although it was already known that the elimination of ectopic glomeruli proceeds through the neural activity of OSNs, our present data suggest that Pcdh- $\alpha$ proteins may function in glomerular remodeling in a neural activity-independent fashion. 

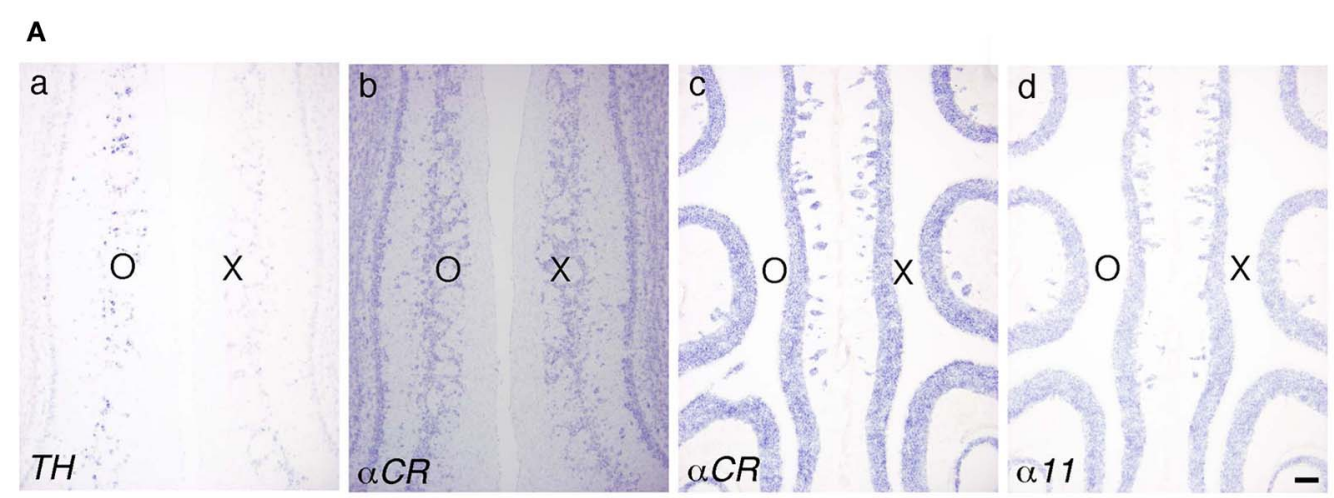

B
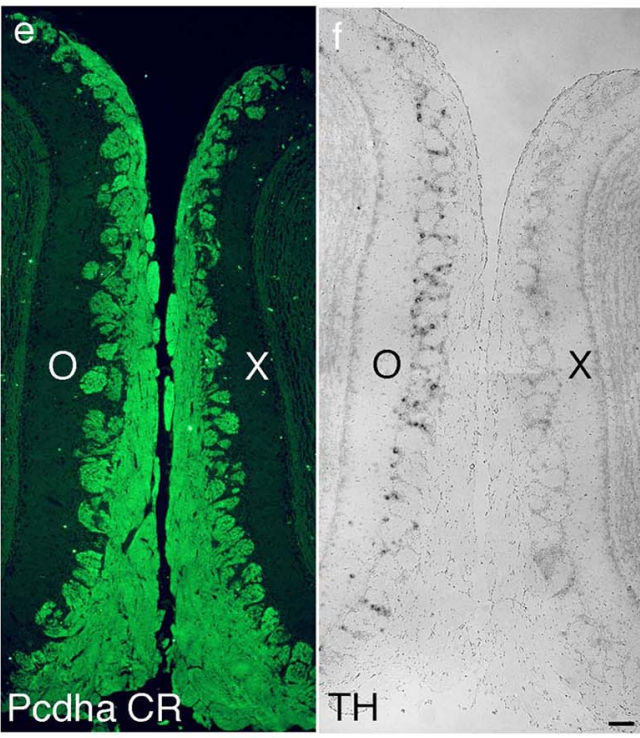

FIGURE 9 | Expression of $P c d h-\alpha$ and the number of M71 and MOR23 glomeruli after naris occlusion of WT and $P c d h$ - $\alpha$-deficient

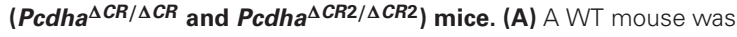
subjected to unilateral naris closure at P21 and analyzed after 1 week. The expression of tyrosine hydroxylase $(T H)$ (a) and $\alpha C R$ transcripts (b) of the closed $(X)$ and open $(O)$ sides in the OB were examined by in situ hybridization histochemistry. The expression of $\alpha 11$ and $\alpha C R$ transcripts in the OE were also examined (c, d). Scale bar, $100 \mu \mathrm{m}$. (B) A WT mouse was subjected to naris occlusion at P5 and analyzed at P30. Pcdh- $\alpha$ immunoreactivity with the anti-Pcdh $\alpha \mathrm{CR}$ antibody was strong in OSN axons and glomeruli in both the closed $(X)$ and open $(O)$ sides at similar levels $(e)$, in
C
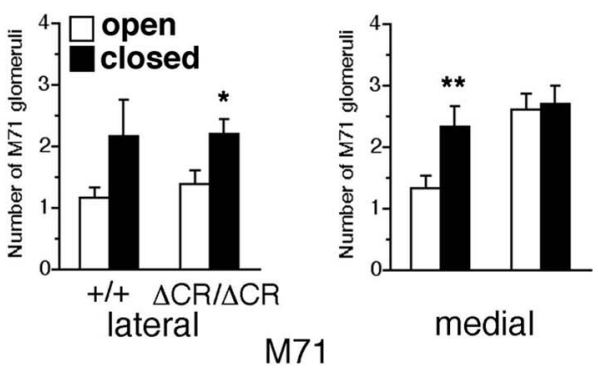

medial
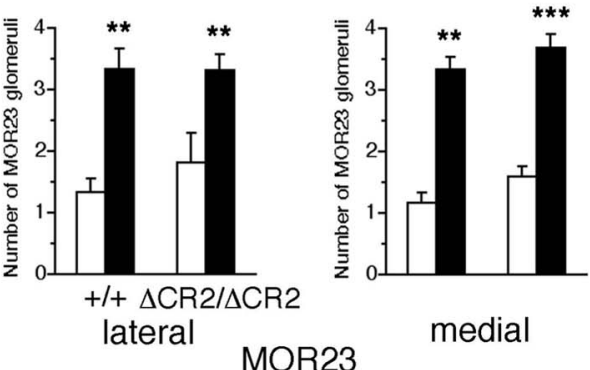

medial

\section{MOR23}

contrast to the change in TH signals (f). Scale bar, $100 \mu \mathrm{m}$. (C) The number of M71 and MOR23 glomeruli per lateral and medial half-bulb of the open (white bars) and closed (black bars) sides after naris occlusion in WT $(+/+)$ and $P C d h$ - $\alpha$-deficient $\left(P C d h a^{\Delta C R / \Delta C R}\right.$ and $P C d h a^{\Delta C R 2 / \triangle C R 2}$ ) mice at P30. Although ectopic glomeruli were further increased in $P C d h a^{\Delta C R / \triangle C R}$

$\left(\triangle C R / \triangle C R\right.$ ) and $P C d h a^{\Delta C R 2 / \triangle C R 2}(\triangle C R 2 / \Delta C R 2)$ mice by the treatment, the total number of glomeruli after treatment was almost the same in the WT and $P c d h-\alpha$-deficient ( $P C d h a^{\Delta C R / \triangle C R}$ and $P c d h a^{\Delta C R 2 / \triangle C R 2}$ ) mice. The number of MOR23 glomeruli in PCdha $\triangle C R 2 / \triangle C R 2$ mice are shown in Table 1.

Significant differences at $* P<0.05$, ${ }^{* *} P<0.01$, and ${ }^{* * *} P<0.001$ calculated by the Mann-Whitney $U$-test.

\section{ROLE OF THE CYTOPLASMIC REGION OF Pcdh- $\alpha$ PROTEINS}

The abnormalities in the axonal coalescence of OSNs in $P c d h a^{\Delta A / \Delta A}$ mice were similar to those of $P c d h a^{\Delta C R / \triangle C R}$ mice, indicating that the cytoplasmic region of the $\mathrm{Pcdh}-\alpha$ protein is essential for the axonal coalescence of homotypic OSNs. The cytoplasmic domain of Pcdh- $\alpha$ is known to bind cytoplasmic signaling proteins of the focal adhesion kinase (FAK) family, FAK and PYK2 (Chen et al., 2009). The FAK family contributes to signaling cascades that regulate growth cones (Chacon and Fazzari, 2011) and membrane stabilization, with PKC and MARCKS (Garrett et al., 2012). Interestingly, MARCKS-like and GAP43 proteins down-stream of PKC are extensively expressed in immature OSNs (McIntyre et al., 2010). Although a role for FAK-PKC signaling has not been reported in OSN axons, it may be involved in regulating coalescence and the elimination of glomeruli.

\section{LOSS OF Pcdh- $\alpha$ MOLECULAR DIVERSITY: DELETION OF EXONS $\alpha 2$ TO $\alpha$ C2 IN THE VARIABLE REGION OF THE Pcdh- $\alpha$ CLUSTER}

In the $P c d h-\alpha$ cluster, the variable region encodes multiple first exons (variable exons) for 14 different $P c d h-\alpha$ isoforms. Each 


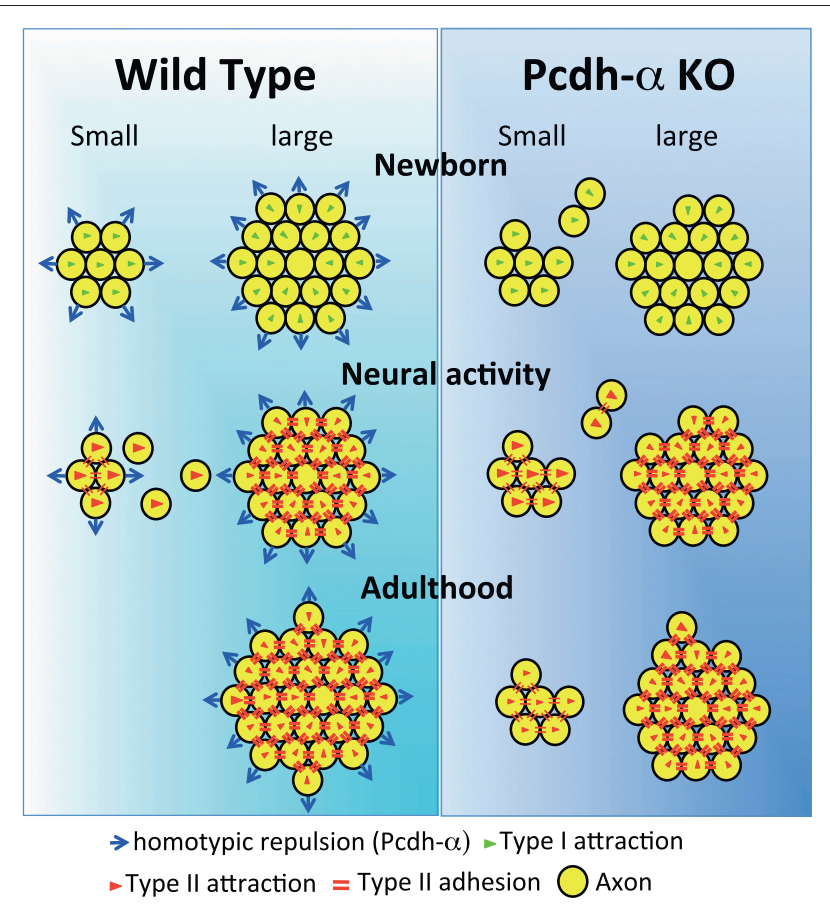

FIGURE 10 | Possible mechanism for the coalescence and elimination of homotypic OSN projections mediated by Pcdh- $\alpha$ proteins. In newborn mice, homotypic OSN axons coalesce by Type I attraction (green triangles). Type I attraction is performed by axon-target interaction by guidance molecules in a graded manner, e.g., Sama3A/Neuropilin1. Pcdh- $\alpha$ protein may elicit a contact-induced repulsion between homotypic OSN axons. In Pcdh- $\alpha$-deficient mice, small glomeruli were generated because the contact-induced repulsive activity did not occur. During development, neural activity promotes Type II attraction (red triangles) and the Type II adhesion (red double-bars) of homotypic OSN projections. Type II attraction depends on axon-axon interactions during contact-induced repulsion between heterotypic OSN axons, e.g., mediated by EphA5/ephrin-A5. Type II adhesion results from the induction of expression of homophilic cell adhesion molecules, e.g., Kirrel2/Kirrel3. In small ectopic glomeruli, these attractive functions promote the correct coalescence of homotypic OSN projections and the elimination of ectopic projections. Pcdh- $\alpha$ protein may help to eliminate small ectopic glomeruli by the contact-induced repulsion of homotypic OSN axons. In adulthood, multiple small ectopic glomeruli disappear in WT mice, but are maintained in Pcdh- $\alpha$-deficient mice. The interdependence of OSN coalescence could result from the balance between the

neural-activity-induced attraction by guidance molecules and the contact-induced repulsion by Pcdh- $\alpha$ proteins in the glomerulus.

variable exon is transcribed from its own promoter and cisspliced to the constant region exons, which are common to all the Pcdh- $\alpha$ isoforms. While the $\alpha 1-\alpha 12$ isoforms are expressed randomly, isoforms $\alpha c 1-\alpha c 2$ are expressesd constitutively in individual Purkinje cells (Esumi et al., 2005; Kaneko et al., 2006). Here we showed that $P c d h-\alpha$ isoforms were also constitutively expressed in the OSNs of the OE, in which the $\alpha 1-\alpha 12$ isoforms were randomly expressed, indicating that the mechanism of $P c d h-\alpha$ gene regulation is similar in Purkinje cells and OSNs. Interestingly, in $P c d h a^{\Delta(2-c 2) / \Delta(2-c 2)}$ mice, in which exons $\alpha 2-$ $\alpha c 2$ in the variable region of the $P c d h-\alpha$ cluster were deleted, the remaining $\alpha 1$ isoform compensated for the others, and was expressed constitutively in neurons including OSNs (Figure 6). Such compensation of missing $P c d h-\alpha$ cluster genes is also found in other deletion mutants, $P c d h a^{\Delta(11-c 2) / \Delta(11-c 2)}$ and $P c d h a^{\Delta(2-11) / \Delta(2-11)}$ (Noguchi et al., 2009). In these mice, the total expression level of $P c d h-\alpha$ isoforms is maintained, and the remaining isoforms compensate for those missing. This compensation can be explained by a mechanism in which a cis-element for regulating the $P c d h-\alpha$ cluster selects one or two gene(s) by binding within the $\alpha 1-\alpha 12$ promoters. In fact, the cis-element for the Pcdh- $\alpha$ cluster was identified as HS5-1 (Ribich et al., 2006), and shown to be regulated in Purkinje cells in vivo (Yokota et al., 2011; Monahan et al., 2012). In addition, a chromatin factor known as CCCTC-binding factor (CTCF) is essential for gene regulation of the $P c d h-\alpha$ cluster (Hirayama et al., 2012). Here, in the $P c d h a^{\Delta(2-c 2) / \Delta(2-c 2)}$ mice, the same $P c d h-\alpha$ gene-regulation mechanisms might function in individual OSNs of the OE and in neurons of the OBs. In any case, the $P c d h a^{\Delta(2-c 2) / \Delta(2-c 2)}$ mice had normal-looking glomeruli in the $\mathrm{OB}$, indicating that the constitutive expression, but not the diversity, of Pcdh- $\alpha$ protein is essential for the axonal coalescence of OSNs and the elimination of small ectopic glomeruli in the olfactory system.

\section{POSSIBLE MECHANISM FOR THE INVOLVEMENT OF Pcdh- $\alpha$ PROTEIN IN THE COALESCENCE AND ELIMINATION OF HOMOTYPIC OSN AXONS}

The development of OSN axon projections and their coalescence into glomeruli from the $\mathrm{OE}$ to the $\mathrm{OB}$ involves several molecular mechanisms regulated by step-wise processes. The stepwise regulation of OSN projection is categorized into type I for immature OSNs and type II for mature OSNs (Sakano, 2010). Immature and mature OSNs that express the same OR possess similar levels of the same guidance cues, and these homotypic axons project and coalesce to the same glomerulus position in the OB (Sakano, 2010).

Pcdh- $\alpha$ proteins may constitutively function to determine the organization of the OSN axon projections. We propose that the $P c d h-\alpha$ family uses a novel mechanism for axonal coalescence and the elimination of ectopic glomeruli for all OR-expressing homotypic OSNs. The coalescence activity enhances the specific topography and OR-signaling-dependent neural activity mediated by guidance molecules (Sakano, 2010). Previously identified olfactory guidance molecules are known to contribute exclusively to the coalescence of homotypic OSN axons into rudimentary glomeruli, in a manner regulated by distinct levels of homophilic and repulsive activities of the ORspecific OSNs. However, no guidance molecules providing the homotypic repulsion for axonal elimination had been identified in the olfactory system. Here we propose that Pcdh- $\alpha$ proteins provide a repulsive activity for all homotypic OSNs and have a counterbalancing effect on the axonal coalescence mechanisms mediated by previously known olfactory guidance molecules (Figure 10). This Pcdh- $\alpha$-mediated signaling provides a novel mechanism for eliminating OR-expressing OSN axons, that is, a repulsive signaling arising from all types of glomeruli that are independent of topography or neural activity. 
Consequently, this hypothesis raises the further possibility that Pcdh- $\alpha$ could be a determinant of the specification of a major (large) glomerulus from other minor (small) glomeruli of homotypic OSNs. Pcdh- $\alpha$ protein is extensively expressed in both the presynaptic side of OSNs and the postsynaptic side of mitral/tufted and periglomerular cells, suggesting it may function in the appropriate maintenance and elimination of synaptic connections in homotypic glomeruli. Therefore, we propose a possible mechanism in which the interdependence of homotypic OSNs in axonal coalescence is ensured by a balance between the neural-activity-induced attraction by many guidance molecules and the contact-induced repulsion by $\operatorname{Pcdh}-\alpha$ proteins in the glomeruli of the OB (Figure 10).

\section{REFERENCES}

Blanchart, A., De Carlos, J. A., and Lopez-Mascaraque, L. (2006). Time frame of mitral cell development in the mice olfactory bulb. J. Comp. Neurol. 496, 529-543.

Buck, L., and Axel, R. (1991). A novel multigene family may encode odorant receptors: a molecular basis for odor recognition. Cell 65, 175-187.

Chacon, M. R., and Fazzari, P. (2011). FAK: dynamic integration of guidance signals at the growth cone. Cell Adh. Migr. 5, 52-55.

Chen, J., Lu, Y., Meng, S., Han, M. H., Lin, C., and Wang, X. (2009). alphaand gamma-protocadherins negatively regulate PYK2. J. Biol. Chem. 284, 2880-2890.

Chess, A., Simon, I., Cedar, H., and Axel, R. (1994). Allelic inactivation regulates olfactory receptor gene expression. Cell 78, 823-834.

Col, J. A., Matsuo, T., Storm, D. R., and Rodriguez, I. (2007). Adenylyl cyclase-dependent axonal targeting in the olfactory system. Development 134, 2481-2489.

Cutforth, T., Moring, L., Mendelsohn, M., Nemes, A., Shah, N. M., Kim, M. M., et al. (2003). Axonal ephrinas and odorant receptors: coordinate determination of the olfactory sensory map. Cell 114, 311-322.

Ebrahimi, F. A., and Chess, A. (2000), Olfactory neurons are interdependent in maintaining axonal projections. Curr. Biol. 10, 219-222.

Esumi, S., Kakazu, N., Taguchi, Y., Hirayama, T., Sasaki, A., Hirabayashi, T., et al. (2005). Monoallelic yet combinatorial expression of variable exons of the protocadherin-alpha gene cluster in single neurons. Nat. Genet. 37, 171-176.

Feinstein, P., Bozza, T., Rodriguez, I., Vassalli, A., and Mombaerts, P. (2004). Axon guidance of mouse olfactory sensory neurons by odorant receptors and the beta2 adrenergic receptor. Cell 117, 833-846.

Feinstein, P., and Mombaerts, P. (2004). A contextual model for axonal sorting into glomeruli in the mouse olfactory system. Cell 117, 817-831.

Garrett, A. M., Schreiner, D., Lobas, M. A., and Weiner, J. A. (2012). gamma-protocadherins control cortical dendrite arborization by regulating the activity of a FAK/PKC/MARCKS signaling pathway. Neuron 74, 269-276.

Hasegawa, S., Hamada, S., Kumode, Y., Esumi, S., Katori, S., Fukuda, E., et al. (2008). The protocadherinalpha family is involved in axonal coalescence of olfactory sensory neurons into glomeruli of the olfactory bulb in mouse. Mol. Cell. Neurosci. 38, 66-79.

Herault, Y., Rassoulzadegan, M., Cuzin, F., and Duboule, D. (1998). Engineering chromosomes in mice through targeted meiotic recombination (TAMERE). Nat. Genet. 20, 381-384.

Hirayama, T., Tarusawa, E., Yoshimura, Y., Galjart, N., and Yagi, T. (2012). CTCF is required for neural development and stochastic expression of clustered $P c d h$ genes in neurons. Cell Rep. 2, 1-13.

Imai, T., Suzuki, M., and Sakano, H. (2006). Odorant receptor-derived cAMP signals direct axonal targeting. Science 314, 657-661.

Kaneko, R., Kato, H., Kawamura, Y., Esumi, S., Hirayama, T., Hirabayashi, T., et al. (2006). Allelic gene regulation of $\mathrm{Pcdh}$-alpha and Pcdh-gamma clusters involving both monoallelic and biallelic expression in single Purkinje cells. J. Biol. Chem. 281, 30551-30560.

Kaneko-Goto, T., Yoshihara, S., Miyazaki, H., and Yoshihara, Y. (2008). BIG-2 mediates olfactory axon convergence to target glomeruli. Neuron 57, 834-846.

\section{ACKNOWLEDGMENTS}

We thank the members of the KOKORO Biology Laboratory for assistance and discussion. We are grateful to P. Mombaerts (Max Planck Institute of Biophysics, Frankfurt) for the P2-IREStaulacZ, M71-IRES-taulacZ, MOR23-IRES-taulacZ, and OMPGFP mice, Y. Yoshihara (RIKEN Brain Science Institute) for the anti-MOR28 and anti-mOR-EG antibodies, T. Izawa for the TH probe, and R. Kaneko (Gunma University) for the generation of targeting vectors. We are grateful to M. Watanabe (Hokkaido University) for the anti-Pcdha CR antibody. This work was supported by Grant-in-Aid for Scientific Research (S), from the Japan Society for the Promotion of Science (JSPS) (Takeshi Yagi), and CREST-JST (Takeshi Yagi).

Katori, S., Hamada, S., Noguchi, Y., Fukuda, E., Yamamoto, T., Yamamoto, H., et al. (2009). Protocadherin-alpha family is required for serotonergic projections to appropriately innervate target brain areas. J. Neurosci. 29, 9137-9147.

Kohmura, N., Senzaki, K., Hamada, S., Kai, N., Yasuda, R., Watanabe, M., et al. (1998). Diversity revealed by a novel family of cadherins expressed in neurons at a synaptic complex. Neuron 20, 1137-1151.

Lin, D. M., Wang, F., Lowe, G., Gold, G. H., Axel, R., Ngai, J., et al (2000). Formation of precise connections in the olfactory bulb occurs in the absence of odorant-evoked neuronal activity. Neuron 26, 69-80.

Malnic, B., Hirono, J., Sato, T., and Buck, L. B. (1999). Combinatorial receptor codes for odors. Cell 96 713-723.

McIntyre, J. C., Titlow, W. B., and McClintock, T. S. (2010). Axon growth and guidance genes identify nascent, immature, and mature olfactory sensory neurons. J. Neurosci. Res. 88, 3243-3256.

Mombaerts, P. (2006). Axonal wiring in the mouse olfactory system. Annu. Rev. Cell. Dev. Biol. 22, 713-737.

Mombaerts, P., Wang, F., Dulac, C., Chao, S. K., Nemes, A. Mendelsohn, M., et al. (1996). Visualizing an olfactory sensory map. Cell 87, 675-686.

Monahan, K., Rudnick, N. D., Kehayova, P. D., Pauli, F., Newberry, K. M., Myers, R. M., et al. (2012). Role of CCCTC binding factor (CTCF) and cohesin in the generation of single-cell diversity of protocadherin-alpha gene expression. Proc. Natl. Acad. Sci. U.S.A. 109, 9125-9130.

Murata, Y., Hamada, S., Morishita, H., Mutoh, T., and Yagi, T. (2004) Interaction with protocadheringamma regulates the cell surface expression of protocadherin-alpha. J. Biol. Chem. 279, 49508-49516.

Noguchi, Y., Hirabayashi, T., Katori, S., Kawamura, Y., Sanbo, M., Hirabayashi, M., et al. (2009). Total expression and dual generegulatory mechanisms maintained in deletions and duplications of the Pcdha cluster. J. Biol. Chem. 284, 32002-32014.

Philpot, B. D., Lim, J. H., Halpain, S., and Brunjes, P. C. (1997). Experience-dependent modifications in MAP2 phosphorylation in rat olfactory bulb. J. Neurosci. 17, 9596-9604.

Ressler, K. J., Sullivan, S. L., and Buck, L. B. (1994). Information coding in the olfactory system: evidence for a stereotyped and highly organized epitope map in the olfactory bulb. Cell 79, 1245-1255.

Ribich, S., Tasic, B., and Maniatis, T. (2006). Identification of longrange regulatory elements in the protocadherin-alpha gene cluster. Proc. Natl. Acad. Sci. U.S.A. 103, 19719-19724.

Sakano, H. (2010). Neural map formation in the mouse olfactory system. Neuron 67, 530-542.

Schwarting, G. A., Kostek, C., Ahmad, N., Dibble, C., Pays, L., and Puschel, A. W. (2000). Semaphorin $3 \mathrm{~A}$ is required for guidance of olfactory axons in mice. J. Neurosci. 20, 7691-7697.

Schwarting, G. A., Raitcheva, D., Crandall, J. E., Burkhardt, C., and Puschel, A. W. (2004). Semaphorin 3A-mediated axon guidance regulates convergence and targeting of P2 odorant receptor axons. Eur. J. Neurosci. 19, 1800-1810.

Serizawa, S., Miyamichi, K., Takeuchi, H., Yamagishi, Y., Suzuki, M., and Sakano, H. (2006). A neuronal identity code for the odorant receptor-specific and activitydependent axon sorting. Cell 127, 1057-1069. 
Stone, D. M., Wessel, T., Joh, T. H., and Baker, H. (1990). Decrease in tyrosine hydroxylase, but not aromatic L-amino acid decarboxylase, messenger RNA in rat olfactory bulb following neonatal, unilateral odor deprivation. Brain Res. Mol. Brain Res. 8, 291-300.

Sugino, H., Hamada, S., Yasuda, R. Tuji, A., Matsuda, Y., Fujita, M., et al. (2000). Genomic organization of the family of CNR cadherin genes in mice and humans. Genomics 63 75-87.

Takeuchi, H., Inokuchi, K., Aoki, M. Suto, F., Tsuboi, A., Matsuda, I., et al. (2010). Sequential arrival and graded secretion of Sema3F by olfactory neuron axons specify map topography at the bulb. Cell 141, 1056-1067.

Taniguchi, M., Nagao, H., Takahashi, Y. K., Yamaguchi, M., Mitsui, S., Yagi, T., et al. (2003). Distorted odor maps in the olfactory bulb of semaphorin 3A-deficient mice. J. Neurosci. 23, 1390-1397.
Vassar, R., Chao, S. K., Sitcheran, R., Nunez, J. M., Vosshall, L. B., and Axel, R. (1994). Topographic organization of sensory projections to the olfactory bulb. Cell 79, 981-991.

Walz, A., Rodriguez, I., and Mombaerts, P. (2002). Aberrant sensory innervation of the olfactory bulb in neuropilin-2 mutant mice. J. Neurosci. 22, 4025-4035.

Wu, Q., and Maniatis, T. (1999). A striking organization of a large family of human neural cadherinlike cell adhesion genes. Cell 97, 779-790.

Yagi, T. (2012). Molecular codes for neuronal individuality and cell assembly in the brain. Front. Mol. Neurosci. 5:45. doi: 10.3389/fnmol.2012.00045

Yokota, S., Hirayama, T., Hirano, K., Kaneko, R., Toyoda, S., Kawamura, Y., et al. (2011). Identification of the cluster control region for the protocadherinbeta genes located beyond the protocadherin-gamma cluster. J. Biol. Chem. 286, 31885-31895.

Yu, C. R., Power, J., Barnea, G., O'Donnell, S., Brown, H. E., Osborne, J., et al. (2004). Spontaneous neural activity is required for the establishment and maintenance of the olfactory sensory map. Neuron 42, 553-566.

Zheng, C., Feinstein, P., Bozza, T., Rodriguez, I., and Mombaerts, P. (2000). Peripheral olfactory projections are differentially affected in mice deficient in a cyclic nucleotidegated channel subunit. Neuron 26, 81-91.

Zou, D. J., Feinstein, P., Rivers, A. L., Mathews, G. A., Kim, A., Greer, C. A., et al. (2004). Postnatal refinement of peripheral olfactory projections. Science 304 1976-1979.

Conflict of Interest Statement: The authors declare that the research was conducted in the absence of any commercial or financial relationships that could be construed as a potential conflict of interest.

Received: 23 August 2012; accepted: 27 September 2012; published online: 16 October 2012.

Citation: Hasegawa S, Hirabayashi T, Kondo T, Inoue K, Esumi S, Okayama A, Hamada $S$ and Yagi $T$ (2012) Constitutively expressed Protocadherin$\alpha$ regulates the coalescence and elimination of homotypic olfactory axons through its cytoplasmic region. Front. Mol. Neurosci. 5:97. doi: 10.3389/ fnmol.2012.00097

Copyright (c) 2012 Hasegawa, Hirabayashi, Kondo, Inoue, Esumi, Okayama, Hamada and Yagi. This is an open-access article distributed under the terms of the Creative Commons Attribution License, which permits use, distribution and reproduction in other forums, provided the original authors and source are credited and subject to any copyright notices concerning any third-party graphics etc. 